\title{
Evolution and dynamics of tropical river plumes in the Great Barrier Reef: An integrated remote sensing and in situ study
}

\author{
D. M. Burrage, ${ }^{1,2}$ M. L. Heron, ${ }^{3}$ J. M. Hacker, ${ }^{4}$ T. C. Stieglitz, ${ }^{1}$ C. R. Steinberg, ${ }^{1}$ \\ and A. Prytz ${ }^{3}$ \\ Received 14 May 2001; revised 31 May 2002; accepted 6 June 2002; published 30 November 2002.
}

[1] The short-lived but intense discharge of freshwater from tropical rivers into the Great Barrier Reef (GBR) Lagoon and the associated salinity reductions are a critical consideration in marine research and management of the ecologically sensitive GBR World Heritage Area. Salinity provides a unique tracer that gives clues to the origin of river-borne contaminants and allows the influences of storm-induced resuspension and river discharge on turbidity to be clearly distinguished. We describe a field investigation of the evolution and dynamics of the Herbert River plume in the central GBR. Its primary goals were to use an airborne salinity mapper and in situ instruments to study the three-dimensional structure and evolution of the plume and to lay a foundation for numerical modeling studies of its dynamics. The aircraft surveys provided a rapid assessment of the plumes spatial extent, while the in situ data revealed details of its subsurface structure. The Herbert River plume was produced by heavy rainfall associated with tropical storms during the La Nina-dominated 1999/2000 monsoon season. In the near field, the surface expression of the plume boundaries was indicated by sharp color and salinity fronts that were clearly visible from the air and sea surface. In the far field and middle Lagoon, the plume was more dispersed and ultimately merged with the larger-scale salinity gradients and with the remnant plume of the more distant, and larger, Burdekin River. The plume location and structure evolved in response to changing river flows, tidal and subtidal circulation, and wind. Using Garvine's Kelvin number-based scheme, the plume was classified as intermediate in dynamical character and thus is subject to a variety of forcings. The plume evolved in response to changes in the relative intensity of tidal currents and low-frequency circulation due to wind and western boundary current forcing. It also displayed a characteristic "hook-shaped" structure, which has been identified previously in numerical plume model studies. This structure appeared in the presence of accelerating along-shelf current flow and horizontal shear and it indicates that the plume circulation had a strongly three-dimensional character. The approach demonstrates the efficacy of combining airborne and in situ methods to observe rapidly evolving coastal salinity structure and dynamics and sets the stage for future satellite-borne studies of larger-scale features showing contrasting salinity distributions. INDEX TERMS: 4219 Oceanography: General: Continental shelf processes; 4275 Oceanography: General: Remote sensing and electromagnetic processes (0689); 4279 Oceanography: General: Upwelling and convergences; 4528 Oceanography: Physical: Fronts and jets; KEYWORDS: front, plume, convergence, salinity, surface, dynamics

Citation: Burrage, D. M., M. L. Heron, J. M. Hacker, T. C. Stieglitz, C. R. Steinberg, and A. Prytz, Evolution and dynamics of tropical river plumes in the Great Barrier Reef: An integrated remote sensing and in situ study, J. Geophys. Res., 107(C12), 8016, doi:10.1029/2001JC001024, 2002.

\footnotetext{
${ }^{1}$ Australian Institute of Marine Science, Townsville, Queensland, Australia.

${ }^{2}$ Now at Department of Marine Science, University of Southern Mississippi, Stennis Space Center, MS, USA.

${ }^{3}$ School of Mathematical and Physical Sciences, James Cook University, Townsville, Queensland, Australia.

${ }^{4}$ Airborne Research Australia, Flinders University, Adelaide, South Australia, Australia.

Copyright 2002 by the American Geophysical Union. 0148-0227/02/2001JC001024\$09.00
}

\section{Introduction}

[2] The significance of salinity for oceanographic studies of the Australian tropical seas spans a wide range of scientific disciplines, and a variety of temporal and spatial scales. Fluctuations in the intensity of river inflows, direct precipitation and evaporation affect the health and status of the region's coral ecosystems. Interannual variation in the drought/flood cycle associated with basin-scale climatic processes such as ENSO is a strong determinant of success in Australian primary industry, and it impacts significantly 


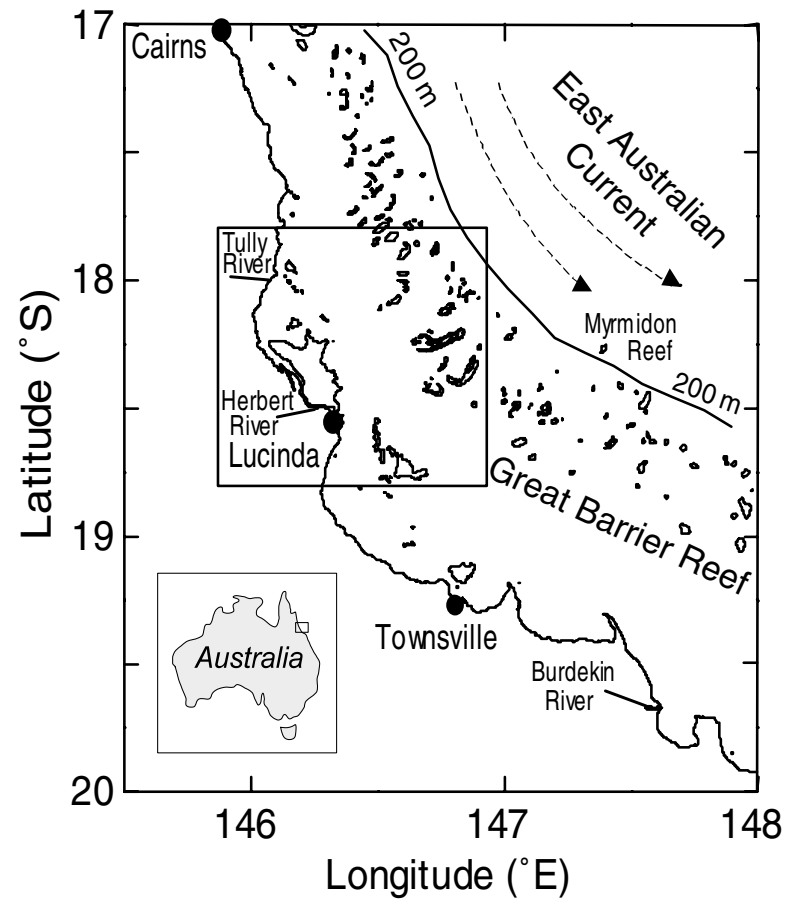

Figure 1. Map of the central GBR region showing location of study area and in situ sampling domain (inset, see Figure 2 for details).

on engineering infrastructure and community health and safety. The formation of barrier layers associated with surface haloclines may significantly limit heat fluxes, particularly in tropical convection zones, where they are formed by excess precipitation [Tomczak and Godfrey, 1994]. In both the tropics and subtropics, the alternating Monsoon/Trade wind cycle modulates precipitation and evaporation on seasonal timescales, while interannual changes in the frequency, intensity, and landfall of tropical cyclones (hurricanes) significantly impact community welfare. Freshwater derived from NE Australian and southern Papua New Guinea coastal rivers or from direct precipitation can be mixed with ambient seawater and advected by subbasin-scale circulation, such as in the northern Coral Sea [Donguy and Henin, 1975].

[3] In the tropical NE of Australia (Figure 1), which is rimmed by the extensive Great Barrier Reef (GBR) World Heritage Area, freshwater inputs play a contentious role in determining ecosystem health, with important implications for coastal and coral reef management. Clearing of coastal river basins associated with the rise of agriculture and mining during the last century is thought to have markedly increased discharge of freshwater, suspended sediments and associated nutrients and or contaminants, such as heavy metals, into the GBR Lagoon. Scientific studies are addressing the vexed question of the degree of impact of natural versus man-made changes on the health and status of coral reef and sea grass communities resulting from these riverborne inputs. While these studies have not yet produced a definitive and quantitative answer, it seems likely that both factors have a significant influence [Furnas et al., 1997; Brodie, 1997]. A crucial question is: to what extent do coastal plumes reach across the GBR Lagoon and invade the extensive and largely pristine coral reefs occupying the outer continental shelf? A less crucial, but interesting issue, which could also influence management strategies is the relative influence of direct precipitation versus river runoff in determining the salt balance of the continental shelf waters [Pickard et al., 1977]. Attempts to quantify buoyancy budgets associated with freshwater input into the vast GBR domain $\left(\sim 120 \times 1600 \mathrm{~km}\right.$, spanning $14^{\circ}$ of latitude $)$ and the Coral Sea $\left(1700 \times 3200 \mathrm{~km}\right.$, spanning $30^{\circ}$ of longitude) from either source will likely be aided by a capability to map surface salinity using air and ultimately satellite-borne remote sensing techniques.

[4] Along with the concerns just mentioned, a number of practical issues confront us in observing coastal salinity changes in the tropics. The occurrence of major floods in the GBR region is most commonly associated with sporadic, but not infrequent, tropical cyclones that invade the coastal domain mostly during summer, particularly in the central GBR (dry tropics). More frequent, sometimes daily, heavy rainfalls along the northern GBR (wet tropics) produce additional base flow with persistent river runoff over the summer months associated with certain rivers (e.g., the Johnstone and Tully Rivers). The unpredictable nature of these events requires a fast and relatively flexible survey approach, which can be adapted to changing conditions. Attempts to map the spatial extent of the major Burdekin River plume during the 1979/1980 and 1980/ 1981 floods using a surface research vessel were successful [Wolanski and Jones, 1981; Wolanski and van Senden, 1983], but inevitably limited in temporal and spatial resolution by ship transit times and safe passages among reefs. Visual airborne surveys, such as those conducted by Brodie [1996] and Brodie et al. [1997] had the advantage of speed, but were limited to the extent that only water color (due mainly to suspended sediment) could be observed, not salinity. There is potential difficulty in distinguishing plumes produced by in situ resuspension of seabed sediments by wind and wave action, from those carrying suspended sediments associated with freshwater runoff. Such ambiguity can best be resolved by sensing surface salinity directly. In spite of this difficulty, Brodie's work demonstrated that strong winds may control the areal extent and direction of migration of the plumes, and raised the possibility that under certain wind conditions plumes could reach outer continental shelf barrier reefs, located at distances up to about $80 \mathrm{~km}$ offshore.

[5] Only a few recent field studies of river plumes have effectively combined in situ sampling methods with remote sensing of surface variables such as temperature, salinity and roughness. Masse and Murthy [1990, 1992] employed hydrographic profiles, current meter moorings and satellite thermal imagery to study the Niagara River Plume in Lake Ontario, which, like the Whale River Plume [Ingram, 1981] and in contrast to the Connecticut plume [Garvine and Monk, 1974], extended to the bed at its source. The momentum balance was shown to evolve from an inertial/Coriolis turning region near the mouth to an essentially geostrophic balance seaward and downstream; occasionally strong downwelling- or upwellingfavorable winds forced the plume, respectively, to either hug the coast or migrate offshore. More recently, Marmorino and Trump [1996] and O'Donnell et al. [1998] have 
succeeded in resolving the dominant motion and density scales of the James and Connecticut River fronts, respectively using high-resolution towed, ship mounted and plume following arrays of ADCP and CTD instruments to observe surface convergence features. They found typical horizontal scales, sinking velocities and strain rates in the frontal zone of $6 \mathrm{~m}, 15 \mathrm{~cm} \mathrm{~s}^{-1}$, and $0.04 \mathrm{~s}^{-1}$, respectively. Marmorino et al. [2000] combined these in situ techniques with airborne real aperture radar imaging to study evolution of the inshore front of the Chesapeake Bay outflow.

[6] The development of technology to remotely sense sea surface salinity and soil moisture using passive microwave radiometry has a relatively long history that began with experiments in the late 1960s and followed in the late 1970s, with deployments of radiometers over the Mississippi River outfall and Chesapeake Bay, and on Skylab [Lerner and Hollinger, 1977; see Lagerloef et al., 1995, Burrage et al., 2000 for more details]. Since then, there have been significant improvements in instrument sensitivity, accuracy, and levels of sophistication, including provision of an imaging capability. These developments, combined with the successes of oceanographic mapping applications [e.g., Goodberlet et al., 1997; Le Vine et al., 1998; Miller, 2000] have recently stimulated successful proposals for satellite-borne instruments [e.g., Font et al., 2000].

[7] The development of a capability to map sea surface salinity remotely, using light aircraft, provides a unique opportunity to map river plumes rapidly as they evolve in space and time. We describe here the first such mapping operations carried out in Australian coastal seas using an airborne passive microwave radiometer system. The instrument employed, the Scanning Low-Frequency Microwave Radiometer (SLFMR) was constructed for an Australian research consortium by ProSensing Incorporated (formerly Quadrant Engineering Inc.) of Amherst, MA, USA. The effort builds upon recent U.S. coastal mapping experience using the prototype SLFMR. This instrument [Goodberlet and Swift, 1993], has been used to map salinity from a DeHavilland Beaver aircraft flying over U.S. east and south coast estuaries and coastal waters [Goodberlet et al., 1997; Miller et al., 1998; Miller, 2000]. The design of the SLFMR is described by Goodberlet and Swift [1993] and a functional simulation of the instrument is presented by Burrage et al. [2000].

[8] Field calibration, logistical and sampling details of our application of the Australian SLFMR system is described in a companion paper [Burrage et al., 2002]. That paper (hereafter cited as BHMSP) describes the instrumentation and acquisition of the airborne and in situ data and evaluates the performance of the airborne mapping instrument in relation to its calibration, validation and confounding environmental influences. It also describes the structure and spatial extent of the plume, and assesses the representativeness of the resulting sea surface salinity maps with respect to subsurface structure.

[9] The experiment, which involved intensive surface and subsurface sampling from in situ moorings and shipboard operations in the vicinity of Hinchbrook Island in the GBR Lagoon (Figure 2), was primarily designed as a "live test" of the SLFMR under representative tropical
Australian conditions. However, the resulting oceanographic and remote sensing data set is sufficiently comprehensive to justify an investigation of the plume's evolution and dynamics. The main issues addressed here are the relationship between the prevailing meteorological and oceanographic forcings and related influences to the evolution of the plume, and inferences concerning plume dynamics. Only a brief overview of the sampling methodology is provided here. The reader should refer to BHMSP for details.

\section{Instrumentation and Data Acquisition}

\subsection{Airborne Salinity Mapping}

[10] The airborne surface salinity mapping instrument used was the SLFMR (serial no. 2) built by Quadrant Engineering, now ProSensing Inc. [Goodberlet, 2000a, 2000b, 2000c]. This is a multichannel passive microwave radiometer that observes the brightness temperature of the natural microwave emission from the sea surface. It operates within a radio-quiet $25 \mathrm{MHz}$ wide astronomical band of the microwave spectrum that is centered at a frequency of $1.4 \mathrm{GHz}(21 \mathrm{~cm}$ wavelength). The instrument observes the sea surface by scanning 8 beams at nominal across-track incidence angles of $\pm 61^{\circ}$, $37^{\circ}, 22^{\circ}$, and $8^{\circ}$ from nadir. The outer 2 beams are not used. The emission is a known function of conductivity, which is itself a function of the sea surface physical temperature and salinity [Goodberlet and Swift, 1993]. The surface salinity can thus be inferred, if the physical temperature of the sea surface is independently measured. This is done using an infrared radiometer system flown alongside the microwave system.

[11] The nominal beam width of $15^{\circ}$ produces a beam spot about $0.7 \mathrm{~km}$ in diameter at the surface, depending upon beam incidence angle, at typical flight altitudes of $2000 \mathrm{~m}$. Each beam is sampled for $0.5 \mathrm{~s}$, so that a scan is completed in approximately $4 \mathrm{~s}$. The Noise Equivalent Delta $\mathrm{T}$ (NEDT), which indicates the radiometric resolution, or sensitivity, of the instrument is estimated to be $0.5 \mathrm{~K}$. This translates into a salinity precision of approximately 1 psu [Klein and Swift, 1977]. The absolute accuracy of the instrument, determined empirically from in situ observations, was found to be $\pm 1.5 \mathrm{psu}$ (BHMSP).

[12] The SLFMR was mounted beneath the fuselage of the twin-engined Cessna 404 operated by Airborne Research Australia (ARA). Flight times, altitudes and track orientation were planned to minimize the effects of such environmental influences as Sun glint and reflected galactic emissions, which may contaminate the microwave data at certain times of day. A total of five overflights of the Hinchinbrook Island domain were made in the afternoons of 21/22, 24, 27, and 30 March 2000. The first two flights were part of a mosaic, which extended from Townsville to Brook Islands, the remaining flights specifically targeted the Hinchinbrook Island region. Flights were aligned approximately across-shelf for the first 2 (mosaic) flights and along-shelf for the Hinchinbrook Island flights (Figure 3). Spatial resolution was enhanced over the plume source at the south end of the Island by flying across-shelf at lower altitudes. Mapping flights were of about 4 hour duration, of which 3 were spent on the actual survey. Typical swath widths were $4 \mathrm{~km}$. At a flying height of about $1.5 \mathrm{~km}$, this 


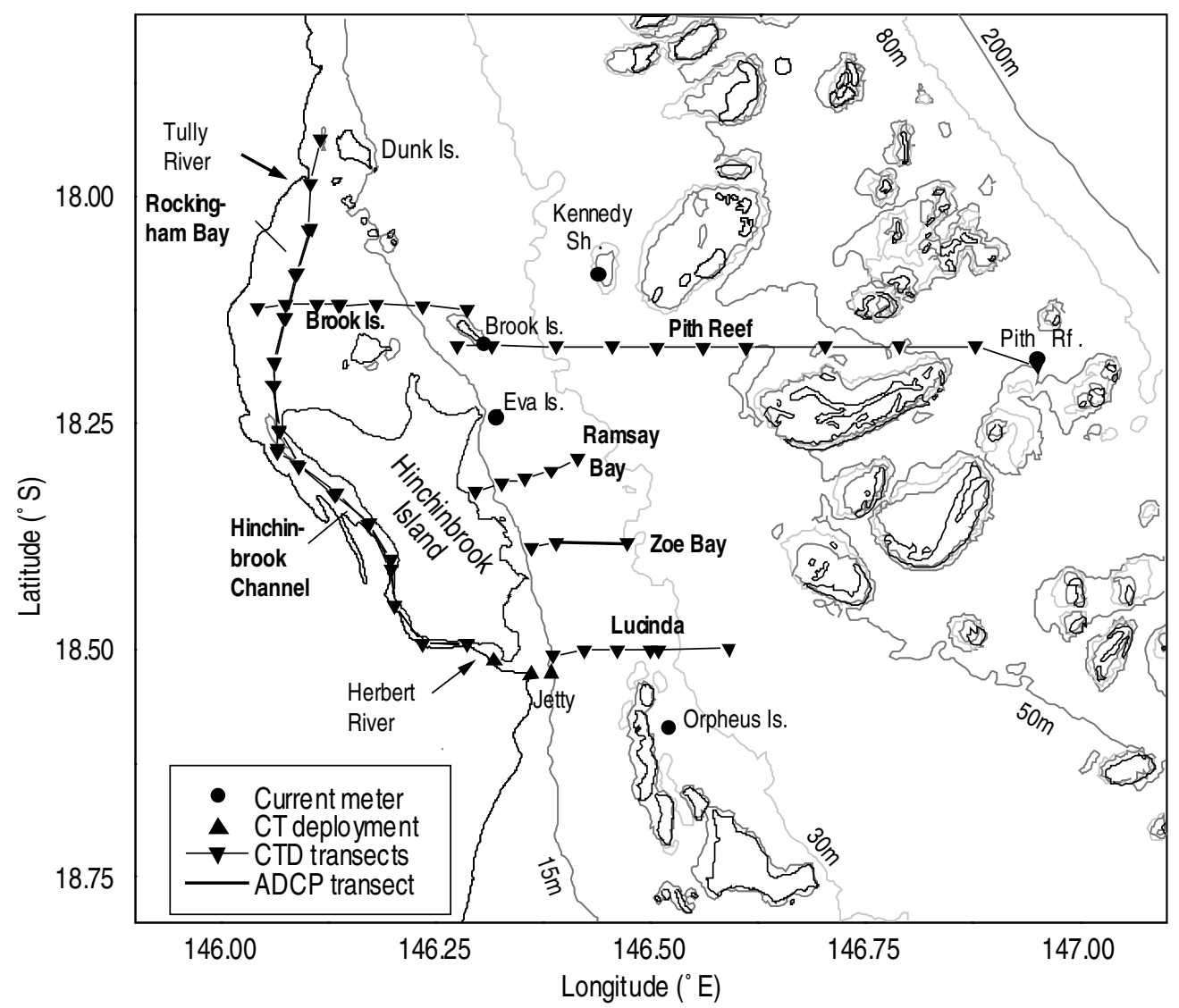

Figure 2. Locations of in situ oceanographic moorings and ship CTD transects within sampling domain in the vicinity of Hinchinbrook Island. Transect labels (bolded) correspond to labels used in Figure 8 and elsewhere. The Eva Island and Pith Reef Current meters were ADCPs. All other current meters were S4s.

enabled an area of approximately $3000 \mathrm{~km}^{2}$ to be covered at a representative cruising speed of $155 \mathrm{kn}$ or $80 \mathrm{~m} \mathrm{~s}^{-1}$. A more detailed discussion of the flight logistics is presented in BHMSP.

\subsection{Oceanographic Sampling}

[13] Oceanographic and meteorological data were acquired using a variety of in situ, fixed or moored, towed and shipboard profiling instrumentation [see BHMSP and Stieglitz and Steinberg, 2001 for details]. The oceanographic mooring locations were chosen to provide data both within the near and far field of the plume, in the ambient shelf waters and at the shelf edge, which is swept by the East Australian Current.

[14] In situ water temperature, salinity and depth were obtained from six Sea Bird Electronics Seacat SBE 16-03 Conductivity and Temperature $(\mathrm{CT})$ recorders and a Sea Bird SBE 19 Seacat Profiler Conductivity Temperature and Depth (CTD) recorder. Sample intervals were $10 \mathrm{~min}$ for the CT and $0.5 \mathrm{~s}$ for the CTD units. The CTD cast data were edited by removing extreme outliers and nearsurface values contaminated by exposure to the air. They were then bin-averaged into $1 \mathrm{~m}$ bins, and smoothed with a 3 or $5 \mathrm{~m}$ long box-car filter, depending upon cast depth.

[15] Tidal and low-frequency currents were observed using a variety of current meter instrumentation. Interocean S4 current meters recording at $30 \mathrm{~min}$ intervals were set near to the surface or close to mid water column depths on conventional taut wire moorings at the locations shown in Figure 2 (see Table 1 for deployment details). Upwardlooking $300 \mathrm{kHz}$ RDI Work Horse Broadband Acoustic Doppler Current Profilers (ADCPs) were set close to the seabed at Eva Island and Pith Reef. These were configured to sample over 25 and $501-\mathrm{m}$ bins, respectively, throughout the water column, with a $10 \mathrm{~min}$ ensemble acquired every $30 \mathrm{~min}$. The last (near-surface) in-water bin was not used due to adverse effects of surface processes on the acoustic response at this level. Data from a third ADCP located at Myrmidon Reef (Figure 1), for a separate long-term mooring study, were also used to capture shelf edge boundary flows associated with the East Australian Current. A fourth $1200 \mathrm{kHz}$ RDI Broadband ADCP was fixed to R/V Titan and used to obtain bottom-tracked velocity measurements both inside and outside the plume. This was configured with $20 \times 1 \mathrm{~m}$ bins with an ensemble time interval of $30 \mathrm{~s}$. Due to commercial trawling activity, site selection for the moorings was restricted so that current meter measurements were only obtained inside the plume at the Brook Island S4 and Eva Island ADCP site.

[16] Marine weather data were acquired from the Australian Bureau of Meteorology weather station at the end of the $5 \mathrm{~km}$ long Lucinda jetty and from a permanent weather station operated by AIMS at Myrmidon Reef. Parameters measured included surface atmospheric pressure, dry and wet bulb temperature, and wind speed and direction (to 


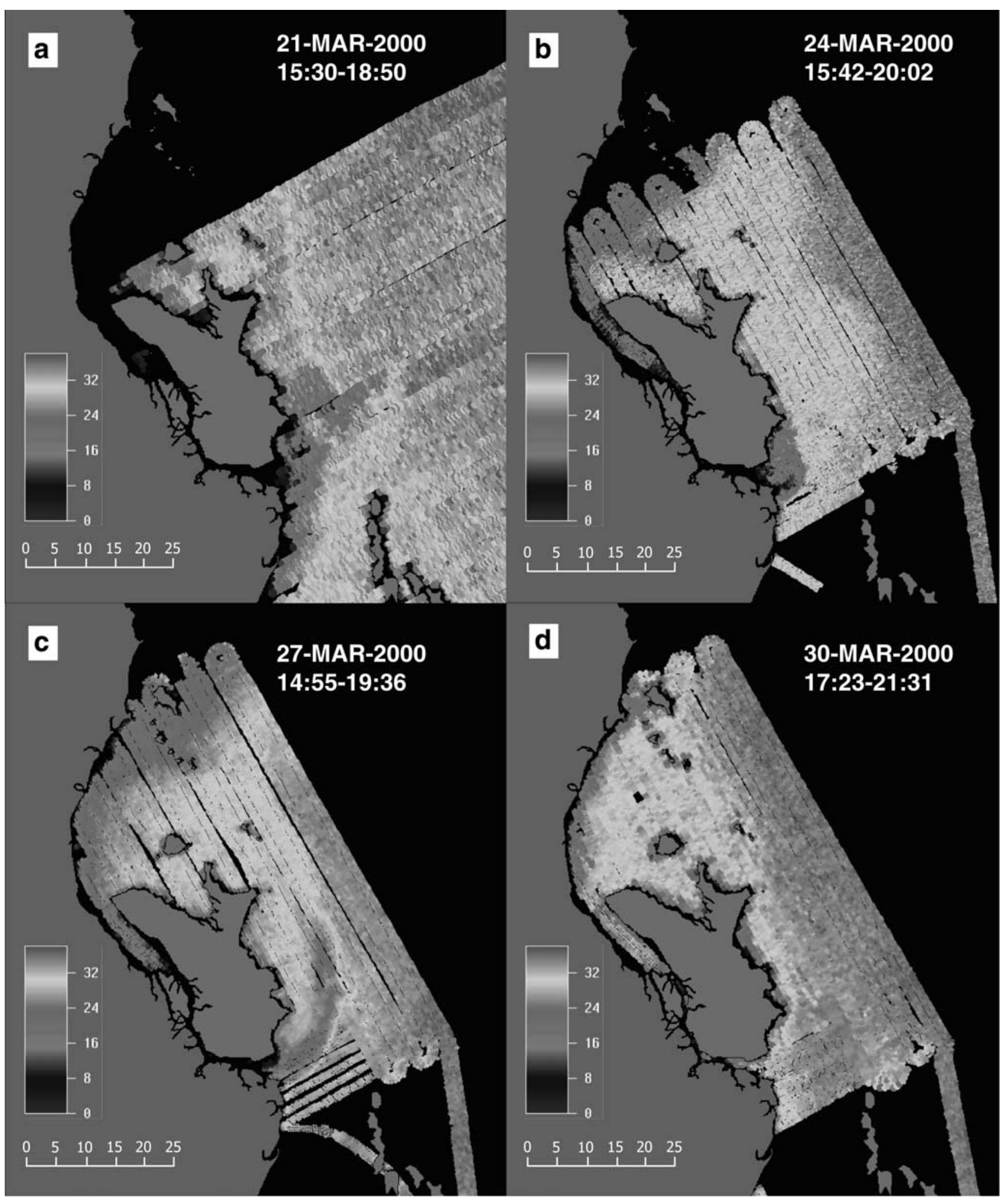

Figure 3. Sea surface salinity maps from the SLFMR. (a) Partial plot of flights 21 and 22 March that were juxtaposed. Subsequent flights on (b) 24 March, (c) 27 March, and (d) 30 March. Strong surface salinity gradients are prominent in all the maps with freshwater $(<16 \mathrm{psu})$ in the Hinchinbrook Channel and along the coasts, and a transition zone of intermediate salinity ( $30-34 \mathrm{psu})$ mark the plume boundary. See color version of this figure at back of this issue. 

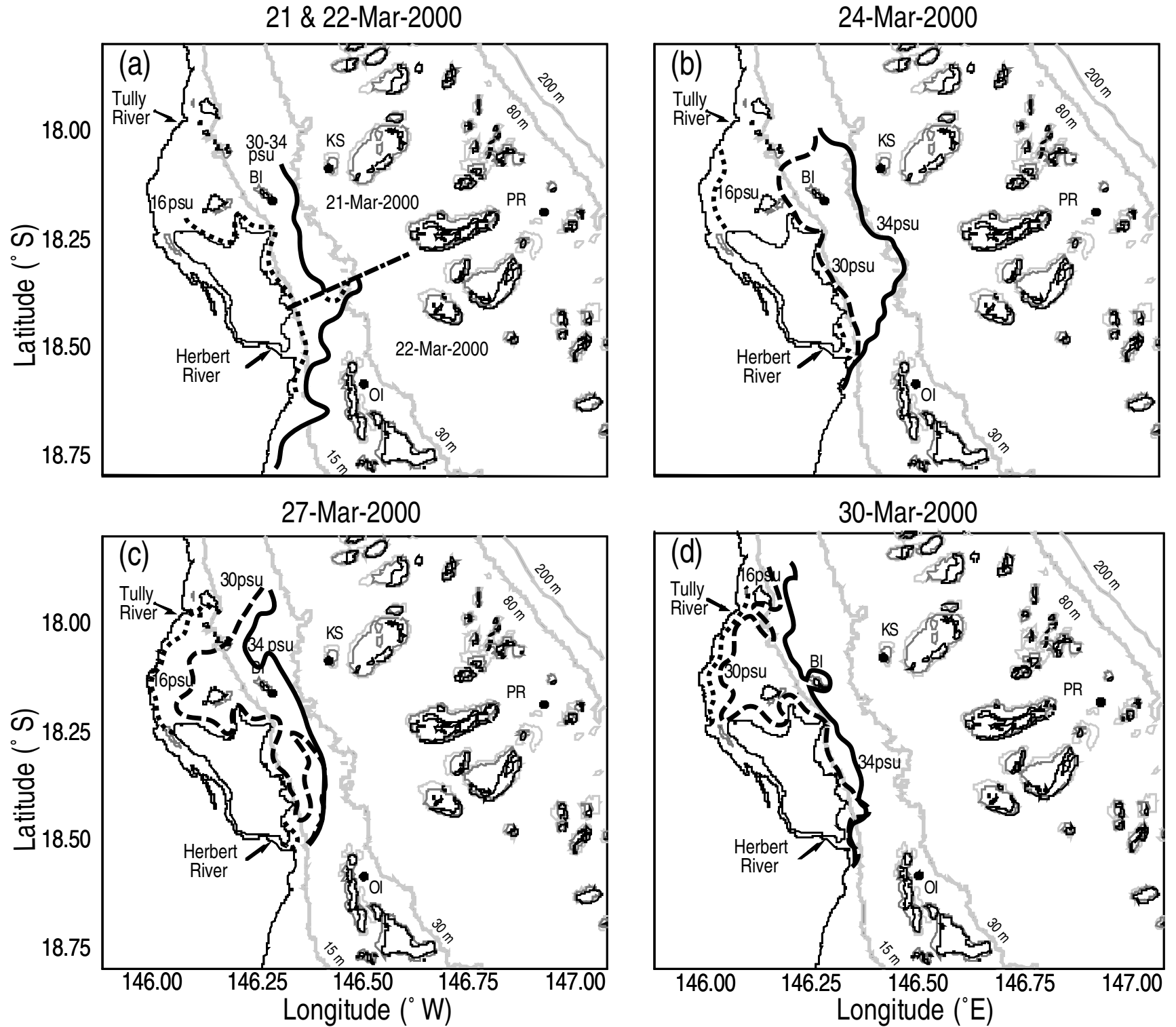

Figure 4. Contour maps identifying the major salinity transitions evident in the corresponding SSS maps (Figure 3). (a) Plume expansion between the first two flights, (b) broadened frontal interface, (c) diminished plume size, and (d) little or no flow emanating from the SE channel entrance.

nearest compass point, i.e., within $22.5^{\circ}$ ). Flow around the Lucinda weather station anemometer, which is located at the end of the jetty, is known to be disturbed by a loading crane when the wind blows from certain quadrants. However, a favorable comparison with the Myrmidon Reef winds, suggests these effects were not significant during the experiment. Standard errors for wind direction and speed are not accurately known, but are likely to be within $\pm 15^{\circ}$ and 2.0 $\mathrm{m} \mathrm{s}^{-1}$, respectively.

[17] Directions given follow meteorological convention for wind velocity (blowing from the given direction), and oceanographic convention for wind stress and currents (acting or flowing toward the given direction). In the Southern Hemisphere, downwelling-favorable wind stress vectors point along the shelf with the coast on their left. This direction, which we refer to as the "downcoast" direction is also the direction in which free (i.e., unforced) coastal-trapped waves propagate. In contrast, upwellingfavorable stress acts in the opposite "upcoast" direction.

[18] Wave data were recorded by the S4 current meter operating in wave mode with a 20 min burst sample every 1 hour at Eva Island. This was processed using an in-house wave analysis program to produce time series of significant and maximum wave height, and zero crossing and mean period [Stieglitz and Steinberg, 2001].

\section{Evolution of the Herbert River Plume}

\subsection{Antecedent and Prevailing Conditions}

[19] Heavy rain associated with a tropical low-pressure system fell at Lucinda during the periods 8-9 and 16-17 March, prior to the mapping experiment (20-31 March). The rainfall rate at Lucinda exceeded $190 \mathrm{~mm}$ (7.5 inches) over the 24 hour period of 17 March. In contrast, the 
Table 1. Moored Instrument Deployment Summary

\begin{tabular}{|c|c|c|c|c|c|c|}
\hline Station name & Symbol & $\begin{array}{c}\text { Start date } \\
(\mathrm{dd} \mathrm{mo}), \text { time } \\
(\mathrm{hh} \mathrm{mm})\end{array}$ & $\begin{array}{l}\text { End date }(\mathrm{dd} \mathrm{mo}), \\
\text { time }(\mathrm{hh} \mathrm{mm})\end{array}$ & $\begin{array}{c}\text { Lat (S) } \\
\text { (dd mm.m) }\end{array}$ & $\begin{array}{c}\text { Lon (E) } \\
(\mathrm{dd} \mathrm{mm} . \mathrm{m})\end{array}$ & $\begin{array}{c}\text { Instrument } \\
\text { position }{ }^{\mathrm{a}} / \text { depth } \\
(\mathrm{m}) \\
\end{array}$ \\
\hline $\begin{array}{l}\text { Kennedy Shoals } \\
\text { Brook Islands } \\
\text { Orpheus Island }\end{array}$ & $\begin{array}{l}\mathrm{KS} \\
\mathrm{BI} \\
\mathrm{OI}\end{array}$ & $\begin{array}{l}20 \text { March, } 1100 \\
20 \text { March, } 1230 \\
21 \text { March, } 1800\end{array}$ & $\begin{array}{l}\text { S4 current meters } \\
5 \text { May, } 0900 \\
5 \text { May, } 1200 \\
7 \text { May, } 0800\end{array}$ & $\begin{array}{ll}18 & 05.18^{\prime} \\
18 & 09.75^{\prime} \\
18 & 35.10^{\prime}\end{array}$ & $\begin{array}{ll}146 & 26.33^{\prime} \\
146 & 18.30^{\prime} \\
146 & 31.20^{\prime}\end{array}$ & $\begin{array}{l}15 / 30 \\
15 / 20 \\
10 / 25\end{array}$ \\
\hline $\begin{array}{l}\text { Pith Reef } \\
\text { Eva Island }\end{array}$ & $\begin{array}{l}\text { PR } \\
\text { EI }\end{array}$ & $\begin{array}{l}20 \text { March, } 2200 \\
24 \text { March, } 1230\end{array}$ & $\begin{array}{l}\text { ADCP current meters } \\
20 \text { September, } 1200 \\
5 \text { May, } 1500\end{array}$ & $\begin{array}{ll}18 & 11.20^{\prime} \\
18 & 14.16^{\prime}\end{array}$ & $\begin{array}{l}14656.91^{\prime} \\
14619.16^{\prime}\end{array}$ & $\begin{array}{l}5 / 50 \\
1 / 20\end{array}$ \\
\hline Eva Island & MY3 & 24 March, 1420 & $\begin{array}{l}S 4 \text { wave recorder } \\
5 \text { May, } 1500\end{array}$ & $1813.5^{\prime}$ & $14720.9^{\prime}$ & $75 / 200$ \\
\hline $\begin{array}{l}\text { Channel } \\
\text { Mid-jetty } \\
\text { End-jetty }\end{array}$ & $\begin{array}{l}\text { CT1 } \\
\text { CT2 } \\
\text { CT3 }\end{array}$ & $\begin{array}{l}30 \text { March, } 1410 \\
31 \text { March, } 1139 \\
30 \text { March, } 1612\end{array}$ & $\begin{array}{l}\text { CT recorders }^{\mathrm{a}} \\
8 \text { May, } 1150 \\
23 \text { April, } 0509 \\
23 \text { April, } 0429\end{array}$ & $\begin{array}{l}1831.90^{\prime} \\
1831.44^{\prime} \\
1831.48^{\prime}\end{array}$ & $\begin{array}{ll}146 & 18.50^{\prime} \\
146 & 21.50^{\prime} \\
146 & 32.10^{\prime}\end{array}$ & $\begin{array}{l}1-3 \\
1-3 \\
1-3\end{array}$ \\
\hline
\end{tabular}

${ }^{a}$ Instrument positions are depth below surface for CT units, but height above bed, otherwise.

experimental period was dry and mostly calm. Further rain associated with the passage of Tropical Cyclone (TC) Tessi fell on the 3-4 April after the airborne mapping operations had been completed (A Tropical Cyclone in Australian usage is equivalent to a hurricane in U.S. terminology). This fortuitous combination of stormy and calm weather enabled us to map a significant flood plume event under near-ideal observational conditions.

[20] The Herbert River flow (Figure 5a) exhibited three peaks exceeding 100,000 ML d $\mathrm{d}^{-1}$ after January 2000 and prior to the commencement of the experiment. The second and largest peak of $748,187 \mathrm{ML} \mathrm{d}^{-1}$, corresponding to a daily average discharge rate of $8660 \mathrm{~m}^{3} \mathrm{~s}^{-1}$, occurred on 29 February, while the third, which occurred on 18 March, 3 days prior to our first flight, was smaller $\left(221,271 \mathrm{ML} \mathrm{d}^{-1}\right.$ or $\left.2561 \mathrm{~m}^{3} \mathrm{~s}^{-1}\right)$. The figure also shows the Tully River flow, which was estimated for the period following the start of the experiment (for which data were not available) on the basis of a $\log 10$ regression against the corresponding Herbert River data for the preceding 3 month period. This was required as an indication of the relative source strengths for the Herbert and Tully River plumes. The regression relationship is considered valid since the upper catchments of these two rivers are of similar geomorphology and experience similar rainfall patterns. The Tully River discharge peaks tend to be an order of magnitude smaller than the corresponding Herbert River peaks, but base flows are of similar magnitude. During the 10 day airborne survey period the Herbert River flow gradually diminished from $50,807 \mathrm{ML} \mathrm{d}^{-1}\left(588 \mathrm{~m}^{3} \mathrm{~s}^{-1}\right.$ to $15,798 \mathrm{ML} \mathrm{d}^{-1}\left(183 \mathrm{~m}^{3}\right.$ $\left.\mathrm{s}^{-1}\right)$. The data thus suggest that local runoff at Lucinda due to rain on 16-17 March augmented the second peak. TC Tessi affected the Townsville area on 2 April, and TC Vaughan hit the coast just south of Lucinda (at the township of Rollingstone) on 5 April. The circulation effects of the latter can be seen in our current meter mooring data. The associated river flow also affected salinities observed from CT units attached to a trawler mooring in the SE arm of Hinchinbrook Channel and to the middle and end of the Lucinda Jetty (Figures 5c-5e). Ignoring tidal advection, the salinity can be seen to vary approximately inversely as the river inflow, with significant freshening occurring in early April and May in association with TCs and storms (compare Figures $5 \mathrm{~b}$ and $5 \mathrm{c}$ ).

[21] The Burdekin River was also running strongly during the experiment (overtopping its dam). This is the largest river in the region and it debouches into the sea south of Townsville $\left(19^{\circ} \mathrm{S}\right.$, see Figure 1). During previous floods the Burdekin plume has been tracked northward far up the coast toward Cairns $\left(17^{\circ} \mathrm{S}\right)$ [Wolanski and Jones, 1981], raising the possibility that as it diffuses and spreads seaward it could lower the ambient shelf water salinities in the vicinity of Hinchinbrook Island. In this case, the Herbert and Tully plumes could be superimposed upon, and ultimately merged with, that of the Burdekin to form a buoyant coastal current that continues further up the coast.

[22] Winds preceding the study period were strong and variable, and ranged generally from 10 to 20 knots in the period 9-20 March. During the period of the second rainfall event (17 March) winds were relatively strong (20-30 knots) and from the NNE (upwelling favorable). They weakened to 10-15 knots and swung to ESE (downwelling favorable) as the river flow peaked on the 18th. After the 20 March they were generally light (less than 10 knots) and from SE to SW. On the 28th they increased again as may be expected during the development and close coastal approach of the tropical cyclones. They remained mostly ESE to SSE before swinging briefly to the NW on 2 April. The winds subsequently swung back to ESE at about 10-20 knots during the remainder of April. The wind stress component resolved into the principal component direction (Figure 6d) shows the period of relative calm that prevailed during all but the last of our salinity mapping flights (conducted on $30 \mathrm{March}$ ).

[23] The low-maximum wave heights recorded at Eva Island $(<0.25 \mathrm{~m}$, Figure $6 \mathrm{e})$ indicate weak wave action during most of the overflights, but heights increased to about $1 \mathrm{~m}$ during the last 3 day flight interval.

[24] Low-frequency currents in the region are driven primarily by wind stress and along-shelf pressure gradient 
(a) Daily River Flow (Megalitres) for First Half of Year 2000

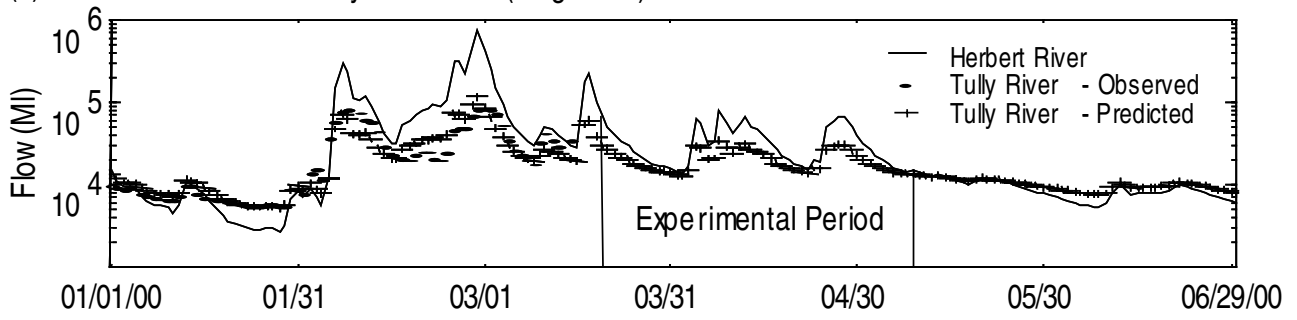

(b) 5 Daily River Flow (Megalitres) for Experimental Period

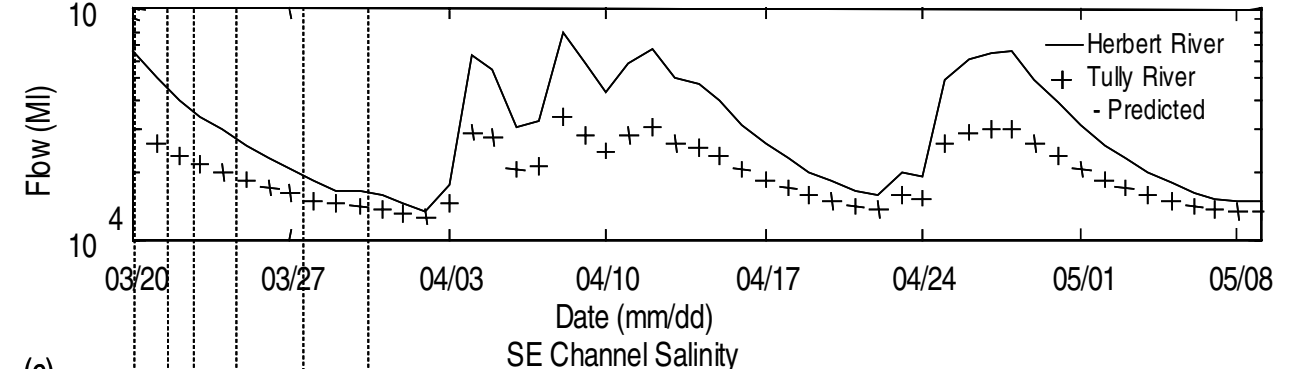

(1)

(1)
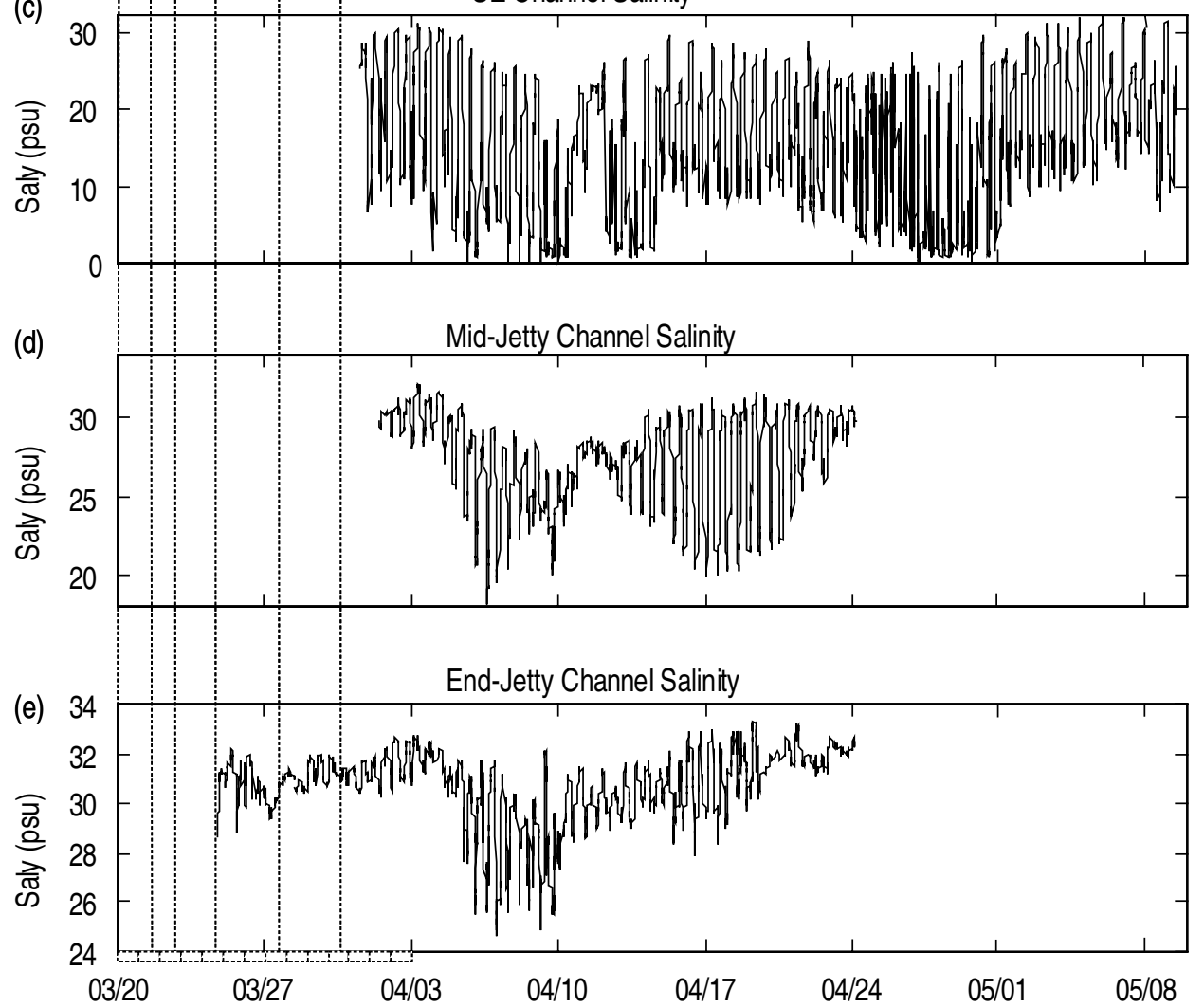

Figure 5. Time series of daily river discharge for the Herbert and Tully River over (a) the first half of 2000 and (b) during the main experimental period. Three periods of high discharge $\left(>60,000 \mathrm{ML} \mathrm{d}^{-1}\right)$ occurred just before and during the experimental period. In situ near-surface salinities from (c) inside the SE channel entrance and at the midpoint (d) and end (e) of Lucinda Jetty show salinities varied approximately inversely with river discharge, with tidal period excursions superimposed. The vertical dashed lines here and in Figures 6 and 10 indicate the times of the SLFMR overflights. The finer graduations along the time axis at bottom left mark daily intervals.

forcing, while the across-shelf momentum balance is essentially geostrophic [Burrage et al., 1991]. In addition to our inner shelf current meter mooring deployments, currents were also observed near the shelf edge at Myr- midon Reef, as part of a separate study. These observations gave a useful indication of the prevailing East Australian Current, which modulates the currents on the continental shelf [Burrage et al., 1991]. Prior to the 

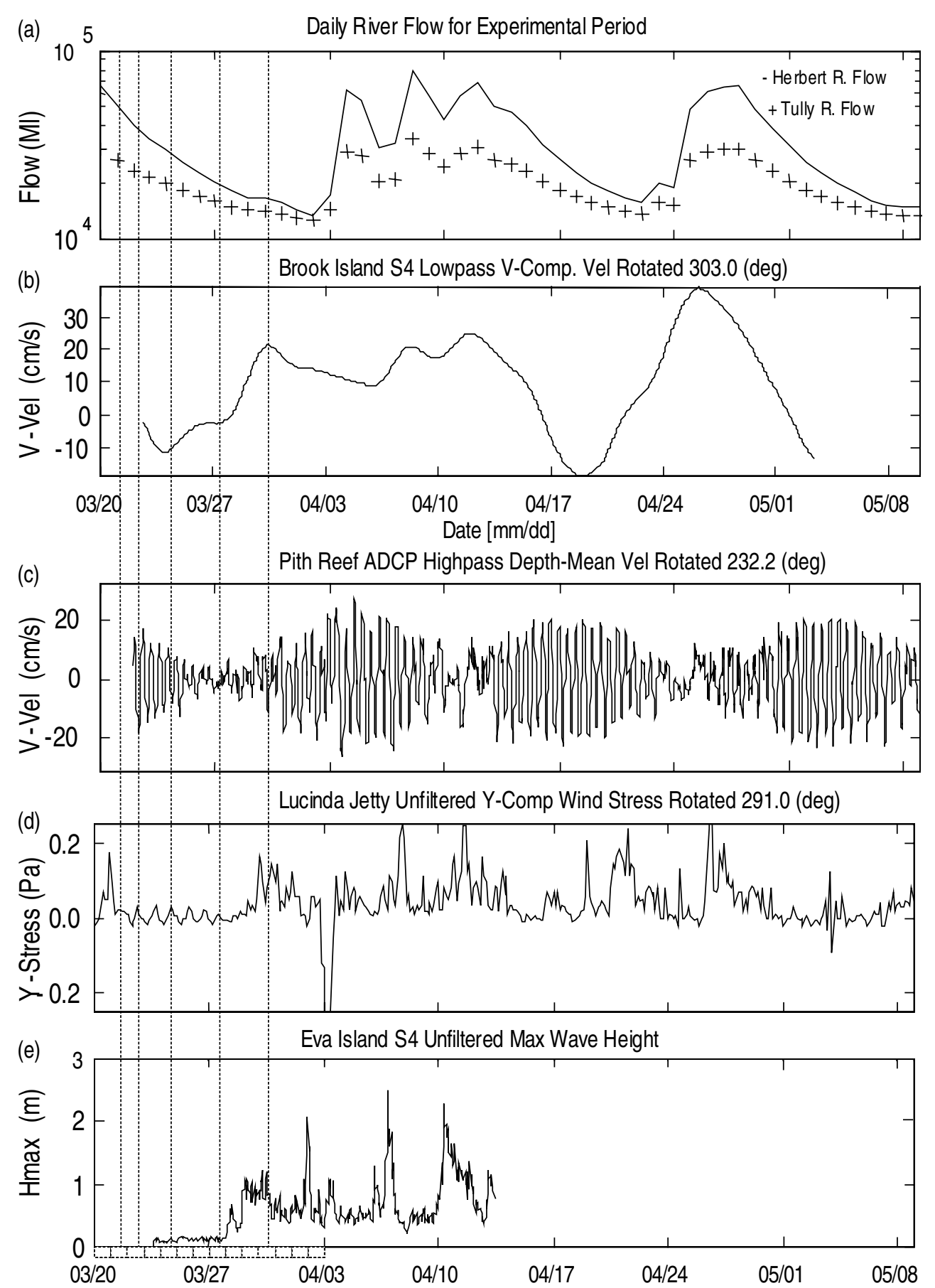

Figure 6. Time series of (a) river flow (repeated from Figure $5 \mathrm{~b}$ for comparison) and forcing functions including (b) low-pass filtered along-shelf current, (c) offshore tidal currents showing prominent springneap cycle, (d) local wind stress, and (e) maximum wave height. Relatively calm dry conditions and weak circulation prevailed during the intensive experimental period (20-30 March) bracketed by strong winds and high discharge, associated with storms, particularly later in the extended period (1 April to 8 May).

airborne mapping experiment currents observed at Myrmidon Reef (see Figure 1 for location) were generally northward but weak 2 weeks prior to the main experiment. They peaked at about $18 \mathrm{~cm} \mathrm{~s}^{-1}$ northward 1 week prior before relaxing to near zero as the mapping flights began. Prevailing low-frequency (wind-driven) currents, PCAlo, during the course of the experiment (Figure 7a) show equatorward vector mean flow, and along-shelf alignment of principal component directions at all stations, while the high-frequency currents, PCAhi, which are dominated by the tides, exhibit significant cross-shelf flow (Figure 7b). This is confirmed by the analysis of major axis tidal current directions and strengths for the $\mathrm{O}_{1}$ and $\mathrm{M}_{2}$ tidal constituents (Figures $7 \mathrm{c}$ and $7 \mathrm{~d}$ ). The dominant $\left(\mathrm{K}_{1}\right)$ 

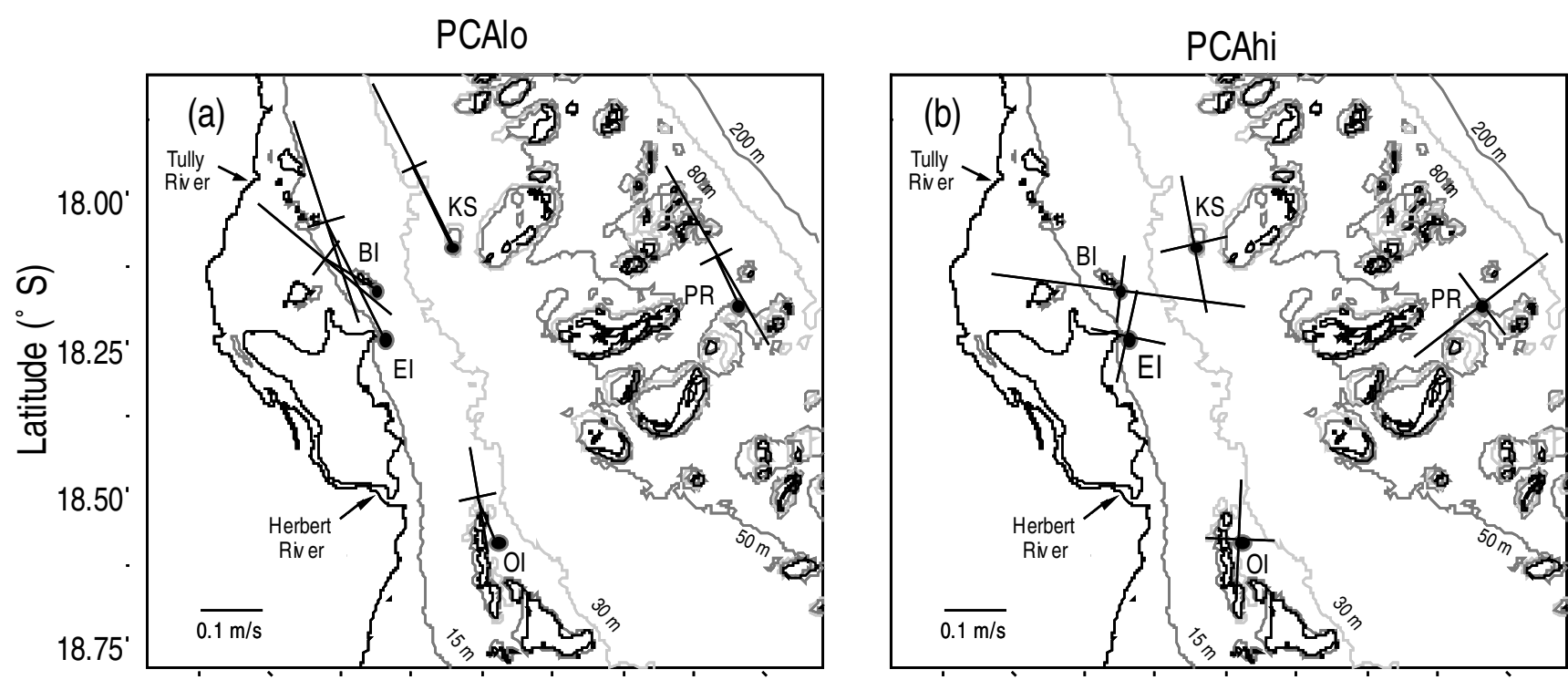

\section{1}
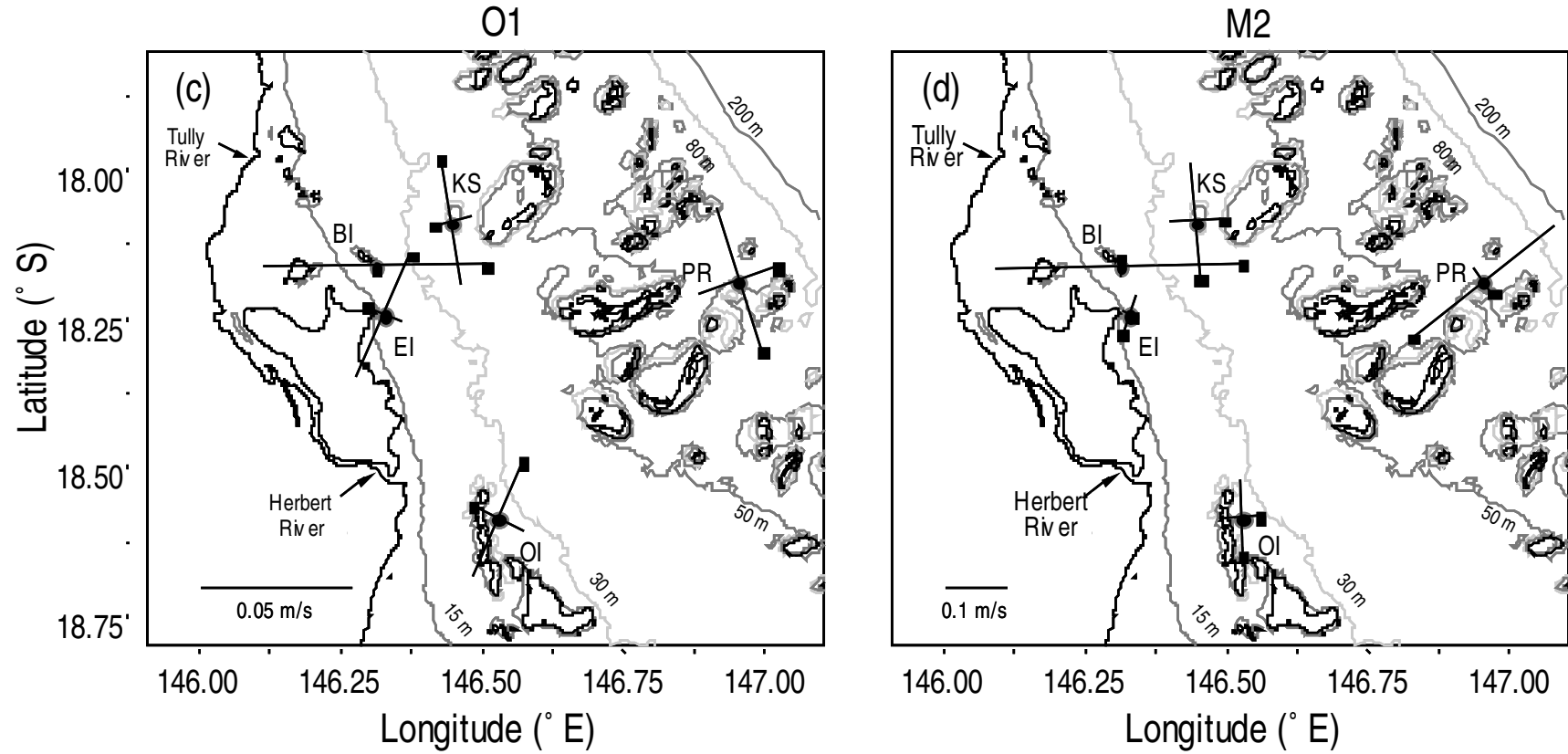

Figure 7. Principle component (PC) directions for (a) low-passed and (b) high-passed current meter data showing major and minor variance principle axes (crosses) computed for each station deployment. The crosses are offset from the station location by a vector representing the mean flow direction and speed. Semimajor and semiminor tidal ellipses are also shown for (c) the diurnal O1 and (d) semidiurnal M2 constituents. The solid squares mark the sense of rotation (polarization) of the velocity vectors with phase referenced to the marked end of the major axis toward the marked minor axis (O1 at BI has clockwise phase progression in contrast to the other stations). PCA hi and M2 principle directions agree closely.

constituent was not resolved by the short records, but $\mathrm{O}_{1}$ should be indicative of diurnal current behavior, while $\mathrm{M}_{2}$ is the dominant semidiurnal constituent.

\subsection{Plume Evolution}

[25] Based on the CTD casts and SLFMR maps we can trace the evolution of the Herbert River plume in considerable detail during the course of the intensive period of the experiment 20-31 March. The experience gained from the intensive period and the in situ time series data collected subsequently allow us to infer likely plume development during the extended period spanning 1 April to 8 May. Finally, the small database of historical data allows us to speculate on what plume conditions might have been like preceding the experiment, i.e., during the first quarter of calendar year 2000, and for the remainder of the wet season, after the experiment was completed.

\subsubsection{Intensive Period}

[26] At the start of the intensive period spanning the SLFMR flights, 20-31 March, the Herbert River plume 


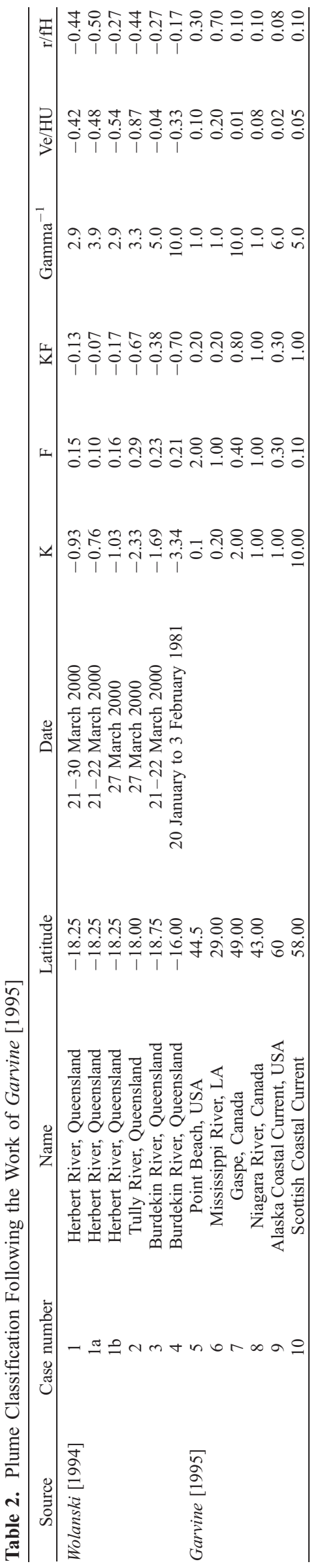

was moderately well developed with a narrow frontal transition of 30-34 psu (Figures $3 \mathrm{a}$ and $4 \mathrm{a}$ ). On the 21 March the river flow had already reduced significantly from a peak established 2 weeks previously (see Figures 5a and $5 b)$. As we had only a few in situ stations operating at this early stage in the experiment, the ancillary data are scant. At this time winds had been moderately strong, but were starting to relax. The tides were relatively intense but diminishing from spring to neap (Figure 6c) and ambient low-frequency currents were weak and tending southward (Figure 6b). After the wind relaxed and a day later, during the 22 March flight (also plotted in Figures 3a and 4a), the plume had expanded; with a doubling of its apparent width, as indicated by the frontal location along the line joining the two flight maps and east of Zoe Bay.

[27] Two days later, on 24 March flight (Figures $3 \mathrm{~b}$ and $4 \mathrm{~b})$, the width of the plume and salinity of its frontal transition zone ( $\sim 32 \mathrm{psu})$, in the southern portion of the domain, closely resembled those mapped on 22 March. However, the interior of the plume was significantly more saline (31 psu compared with about $21 \mathrm{psu}$ ), indicating significant mixing had taken place. In comparison with the situation on 21 March, the $30 \mathrm{psu}$ isohaline had contracted almost to the coast, and the 32 psu isohaline had expanded offshore, so the plume was weaker and more widely dispersed. Conditions remained calm, with weak prevailing currents, and weakening tides. There was also a second bulge located to the north. This could have been caused by a frontal meander, but that is unlikely for a subcritical plume like this (section 5.2 and Table 2). Alternatively, it might have resulted from a merger with another plume emanating either from the NW arm of Hinchinbrook Channel or from the Tully River. A new and much narrower ( $<5 \mathrm{~km}$ wide) frontal plume feature appeared off the SE coast of Hinchinbrook Island, presumably reflecting the existing reduced river inflow rate. Salinities at the end of the $5 \mathrm{~km}$ long jetty (Figure $5 \mathrm{e}$ ) were about $31 \mathrm{psu}$, which is consistent with those mapped immediately seaward of the plume (Figures $3 \mathrm{~b}$ and $4 \mathrm{~b}$ ). During the following 3 days, the area of fresh water $(<16 \mathrm{psu})$ emanating from the SE channel entrance progressively contracted, consistent with the monotonically decreasing river flow (Figure 6a).

[28] By 27 March (Figures 3c and 4c), the broader plume had reintensified, despite the continually reducing river inflow. There was a smoothly curving frontal transition, and salinity inside the front was depressed to 24 from 31 psu. The plume width off the southern half of Hinchinbrook Island had narrowed to $10 \mathrm{~km}$ from a maximum of about 20 $\mathrm{km}$. The appearance of the relatively saline tongue, seeming to penetrate southward between the Island and the front, coincided with the upwelled 29 psu isohaline within the upper 3 or $4 \mathrm{~m}$ of the vertical section off Ramsay Bay (Figure 8c). The appearance of this feature and its likely dynamical implications are considered further in section 5.2. At this time neap tides prevailed (Figure 6c), so tidal mixing was at its minimum for the intensive period.

[29] By 30 March (Figures 3d and 4d), the plume structure was much diminished in both intensity and scale. Stronger northward ambient flow of about $20 \mathrm{~cm} \mathrm{~s}^{-1}$ (Figure 6b) apparently reduced the plume width to the extent that relatively freshwater (order $24 \mathrm{psu}$ ) was confined to a narrow band along the coasts of Hinchinbrook Island and Rockingham Bay. A large, but moderately saline $(\sim 32 \mathrm{psu})$ and 

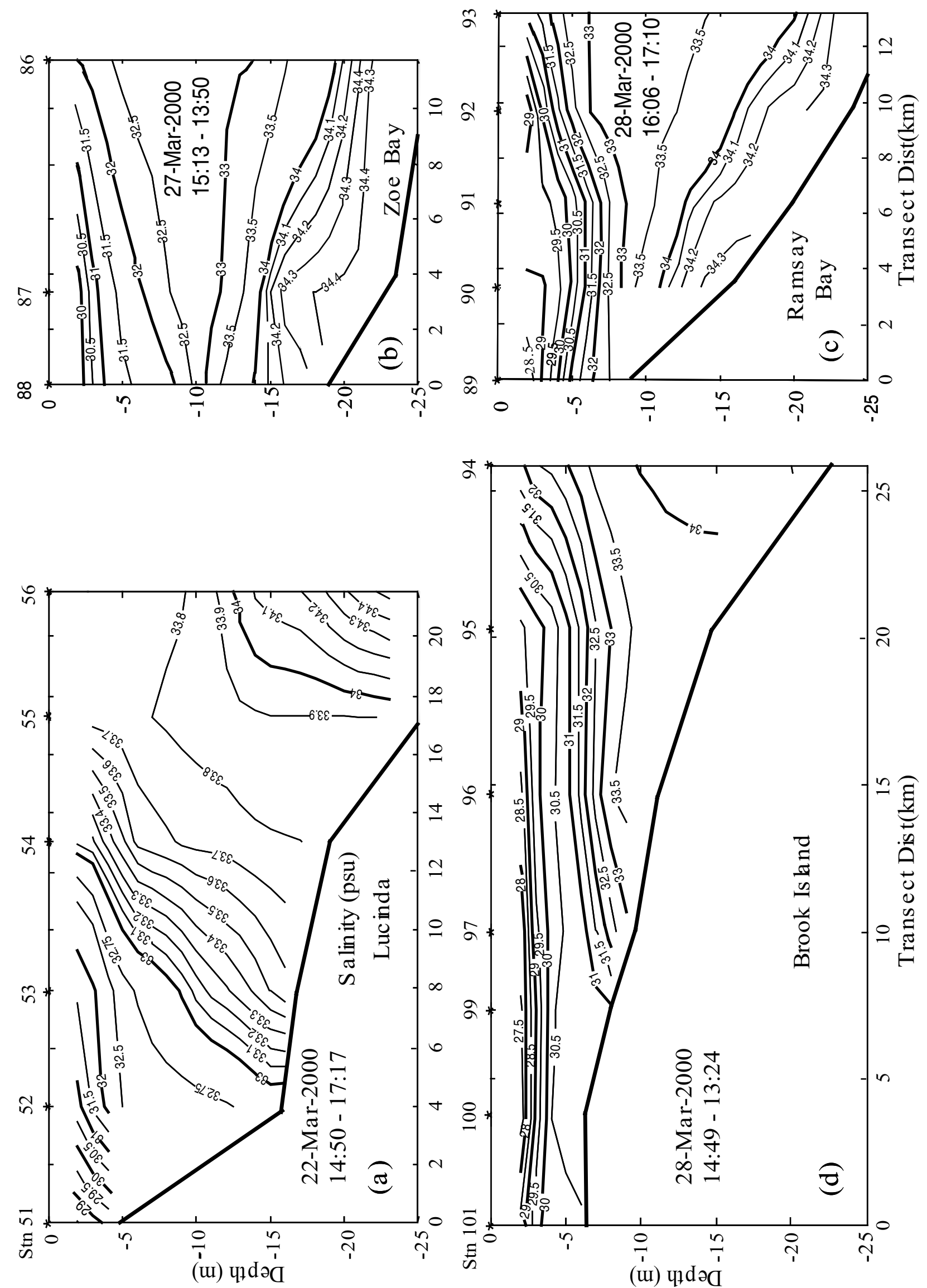
thin $(<5 \mathrm{~m})$, body of buoyant water remained trapped in the Bay. Salinities inside the SE and NE arms of the Channel had risen to about 20 psu from values of less than 14 psu observed on $27 \mathrm{March}$, as a consequence of the reduced discharge of Herbert River waters into the Hinchinbrook Channel.

[30] Clearly, the plume responded to different oceanographic and meteorological conditions that modulated its intensity and location, while the source strength gradually declined. Among these factors the transition from spring to neap tides and back to springs is a significant factor (see Heron et al. (Sea surface salinity remote sensing of river runoff on the Great Barrier Reef, manuscript in preparation, 2002) for an analysis of the effects of tidal mixing on the Herbert River plume), while wind and prevailing ambient current, also play an important role. Under more extreme conditions, such as during the passage of a tropical cyclone in the extended period discussed below, river discharge and wind and wave-induced mixing may well dominate the other factors.

\subsubsection{Extended Period}

[31] The extended period (1 April to 8 May), during which the in situ moorings remained in place, provides a pertinent example of tropical cyclone influence, with the passage of TCs Tessi and Vaughan on the 3 and 6 April, respectively. Prior to the arrival of TC Tessi, river flow was weak, prevailing currents were northward, and tides were in transition from neap to spring. The prevailing wind stress was northward, and similar to its intensity at the start of the period.

[32] Just prior to the arrival of the first cyclone, maximum wave heights attained a peak of about $2 \mathrm{~m}$, and wind stress swung southward. On 3 April, spring tides again prevailed and the southward wind stress reached its maximum for the entire period (Figures $6 \mathrm{c}$ and $6 \mathrm{~d}$ ). Maximum wave heights at Eva Island peaked, at a height of $1 \mathrm{~m}$ (Figure 6e). Since the wave-measuring Eva Island S4 current meter was on the lee side of the island, the fetch was probably quite restricted. Thus wave heights in the region could have been significantly underestimated. Prevailing low-frequency currents weakened slightly, but continued northward (Figure 6b). The river discharges peaked three times during the ensuing week (Figure 6a). As tides changed to neap, the northward current strengthened and wind stress swung around to produce one modest, and two moderately strong, northward pulses. Maximum wave heights peaked in proportion, but the peaks led the wind field. This could be explained by swell propagating shoreward from TCs located offshore that subsequently approached and crossed the coast.

[33] During this period, the Herbert River and estimated Tully River flows regained discharge rates equal to those exhibited at the start of the intensive period (Figure $5 \mathrm{~b}$ ). Salinities inside the SE channel entrance and at Lucinda jetty (Figures $5 \mathrm{c}-5 \mathrm{e}$ ) where modulated by the spring tides, with ranges of 10-30 and 30-32 psu, respectively, but the wave envelope actually peaked as TC Tessi approached. This response would be consistent with the (as yet) weak river inflow and strong tidal mixing. Any residual plume was likely reduced in intensity and compressed against the coast by the combined effects of mixing and along-shelf advection. Due to the wind reversal however, the plume might have moved southward of the channel mouth, but is unlikely to have moved significantly offshore, as the wind pulse was too brief to allow time for offshore surface layer Ekman transport to become established. As the river discharge peaked, the salinity wave envelopes gradually freshened to the point where salinities ranged from 0 to about $22 \mathrm{psu}$ in the SE arm of the Channel and from 25 to 30 psu at the end of the jetty.

[34] By 10 April, after the second northward wind peak resulting from passage of TC Vaughan, the prevailing currents at Brook Island peaked at about $0.18 \mathrm{~m} \mathrm{~s}^{-1}$ northward, while the tides changed to neap, wind became relatively calm, and maximum wave heights were correspondingly small (about $0.3 \mathrm{~m}$ ). The plume, at this stage, may well have been developed to its maximum intensity and extent. With the passage of yet another storm on about the 12 April, waves peaked once again, then gradually diminished, and prevailing currents reached a peak of about $0.20 \mathrm{~m} \mathrm{~s}^{-1}$. In this situation the plume likely experienced strong vertical mixing due to wind wave action, but little tidal mixing because the tides were neap. The response appears to have been a somewhat erratic return to saltier conditions in the SE arm of the channel and at Lucinda, in spite of the significant river discharge.

[35] From about 14 to 24 April, conditions followed a pattern similar to that prevailing during the intensive period, i.e., monotonically diminishing river inputs, gradually increasing plume salinities, a transition to neap tides, and drift currents switching from a southward pulse of $20 \mathrm{~cm}$ $\mathrm{s}^{-1}$ maximum speed to an even stronger northward flow. We thus infer a similar response to that of 12 April, with an initially strong and well-defined northward trending plume changing to one dominated by wind and tidal mixing, and finally, to a weak and narrow coast-hugging plume.

[36] The subsequent flood, beginning with increased river discharge on 25 April, attained the amplitude of the previous peak then declined monotonically, as before. It is interesting that peaks in river discharge tended to correspond to northward along-shelf current flow (at least for 2 cases out of 3 ). Northward flow would naturally be expected if the plume (deflected to the left by Coriolis effects) significantly influenced the low-frequency currents. However, the Brook Island drift current was highly correlated with all of our other ADCP and S4 current meter sites (not shown), regardless of location in or outside the plume and over the continental shelf or slope. The shelf currents were thus unidirectional, and likely influenced by the combined forcing of the along-shelf winds and by the horizontal pressure gradients, which are modulated by the East Australian Current flowing along the shelf

Figure 8. (opposite) Salinity sections (a) starting near the SE channel entrance at Lucinda and proceeding (in clockwise panel order) up the east coast of Hinchinbrook Island past (b) Zoe Bay and (c) Ramsay Bay into (d) Rockingham Bay. The plume intersects bottom near the entrance but floats within the upper $10 \mathrm{~m}$ subsequently, as it flattens to the north then broadens into Rockingham Bay. A retrograde front is apparent offshore at depths exceeding $10 \mathrm{~m}$. Surfacing of the 29 psu isohaline off Ramsay Bay (at Stn 91) coincides with saltier water penetrating the plume from the north in the SSS map acquired on the same day (see Figure $3 \mathrm{c}$ ). 
edge [Burrage et al., 1991, 1994]. If so, the correspondence between discharge and prevailing depth-averaged and/or middepth (i.e., barotropic) current is a mere coincidence. Another possible effect would be equatorward deflection of the Herbert River plume by the larger plume emanating from the Burdekin River mouth, to the south. Hydrodynamic modeling simulations [King et al., 1998, 2000] suggest that the Burdekin's influence can extend northward beyond Hinchinbrook Island and out to, at least, half the width of the GBR Lagoon. While the SLFMR salinity maps (Figure 3) provide some evidence of seawater dilution in the lagoon, south of the SE channel entrance, the map acquired on 27 March (Figure 3c) suggests that the Herbert River plume was isolated from more southern sources during the later half of the survey.

[37] A more subtle baroclinic velocity structure related to the presence of the plume is likely, and easier to substantiate using the shipboard ADCP data (discussed above). While no causal connection is expected between river discharge and the spring-neap cycle, there is a possibility that tidal currents could modulate the low-frequency circulation [Burrage et al., 1991, 1994]. If such a relationship were to be acting here, it could be confounded by the strong northward wind stress associated with passage of the tropical cyclones.

\subsubsection{Historical Period}

[38] We have some data upon which to base an assessment of the historical conditions pertaining to the first quarter of the year. There were two prior river discharge peaks that exceeded those giving rise to the plumes that we observed instrumentally, so we suppose that larger and stronger plumes were likely to have occurred prior to the combined Intensive and Extended observation periods. On the other hand, the discharge peak observed at the end of April was the last significant event for the first half of the calendar year, and marked a return to the SE trade-dominated dry season characterized by relatively low flow, moderately strong but steady on shore prevailing winds, and cool saline conditions.

\section{Tidal and Internal Circulation}

\subsection{Tidal Influence}

[39] The response of the plume to tidal influences in the absence of strong transient events (e.g., due to tropical cyclones), is expected to be determined by passive advection of the salinity field and changes in the stratification due to a variety of physical influences. The tidal period salinity variations (Figure 5) ranged consistently over about 20 psu inside the Channel (Figure 5c), while the range varied from about 1 to $10 \mathrm{psu}$ at the midjetty (Figure $5 \mathrm{~d}$ ) to about $2-5$ psu at the end (Figure 5e). During spring ebb tidal flow the channel instrument occasionally registered essentially pure river water $(<1 \mathrm{psu})$. The channel $\mathrm{CT}$ instrument was suspended from a floating buoy and maintained a nearly constant depth of $1 \mathrm{~m}$ below surface, while the jetty instruments were suspended from the jetty handrail at a depth of about $1 \mathrm{~m}$ below the low tide level. In the latter the depths therefore varied over a range of about 1-3 m. A slightly saline bias, might therefore be expected at the jetty sites. It is likely that almost pure river water was present at all three stations, at least during ebb tide, at certain times in the spring-neap cycle.
[40] The influence of tidal advection and tidally induced current shear (both horizontal and vertical shear of the horizontal currents) are apparent in the S4 and ADCP data. However, the depth-averaged high-pass (tidal band) current at the Eva Island ADCP [Stieglitz and Steinberg, 2001] exhibited quite an irregular tidal cycle, and a relatively indistinct spring-neap cycle. This contrasted with the regular tidal pattern of the depth-averaged currents at Pith Reef ADCP (Figure 6c), which was located outside the plume. This contrast suggests that small-scale circulation features, such as tidal eddies and jets associated with finescale topography and perhaps baroclinic processes, significantly influenced the high-frequency current variability within the plume.

[41] The effects of tidal advection were clearly seen during near-instantaneous observations of current made within the plume, using the ship-mounted ADCP. For example, on the 27 March, when prevailing low-frequency currents were weak, the effect of tidal flood currents was apparent in a reversal of surface flow directions observed along the east coast of the Hinchinbrook Island.

\subsection{Internal Circulation}

[42] The internal circulation of the plume may be represented by mean, time-varying, and instantaneous velocity profiles obtained from the shipboard ADCP and moored CM deployments at Eva Island (inside the plume) and Pith Reef (outside the plume). The mean velocity profile of the major principle component, V-Cmpt (loss-passed), for the full period of record at Eva Island (Figure 9a) shows a uniformly sheared equatorward mean flow of $10-30 \mathrm{~cm} \mathrm{~s}^{-1}$, with the velocity maximum near the surface. This is consistent with the more buoyant surface water in the plume being deflected northward by Coriolis acceleration and/or the effects of the prevailing SE trades. The V-Cmpt profile at Pith Reef (Figure 9b) also shows a mean equatorward flow, but in this case the horizontal velocities and shear are much weaker $\left(6-8 \mathrm{~cm} \mathrm{~s}^{-1}\right)$, and the velocity maximum lies about $10 \mathrm{~m}$ above the bed. The corresponding cross flows, U-Cmpt, show a net shoreward transport with linear shear and stronger flow near the surface (Figure 9b), while the Eva Island profile (Figure 9d) shows a maximum at about $8 \mathrm{~m}$ above the bed. This is at or immediately below the base of the plume interface, which is typically $8 \mathrm{~m}$ below the surface near this location. Clearly there is a "tendency" for stronger shoreward flow, or weaker offshore flow, near the base of the plume. The resulting transverse circulation pattern superficially resembles that of the longitudinal section through a salt wedge estuary with saltier lower layer water encroaching on, and subducting beneath, the more buoyant surface layer.

[43] The contrast between strong shear at Eva Island and weak shear at Pith Reef is clearly evident in the time series of along-shelf flow from the same current meters (compare Figures 10a and 10b). The Pith Reef along-shelf flows are essentially barotropic, while those at Eva Island (inside the plume) are baroclinic. The corresponding cross flows, however, are quite strongly sheared at both locations, i.e., on both sides of the plume front. The high-pass (tidal band) velocity profiles from these stations (not shown), are quite similar to those described above, except that shear is also significant in the along-shelf (tidal) flow at Pith Reef. 


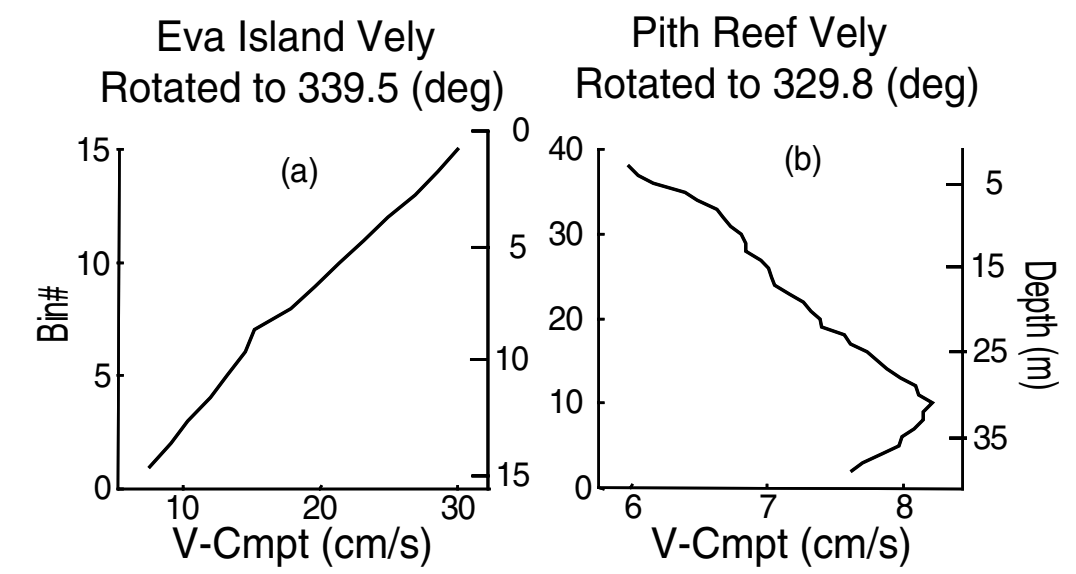

\section{Pith Reef Vely Rotated to 329.8 (deg)}
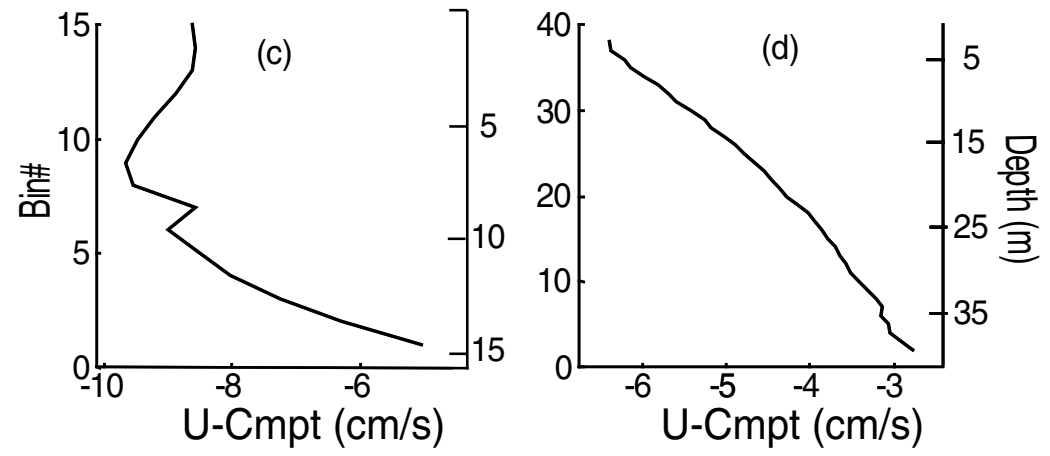

Figure 9. Vertical profiles of time mean low-pass ADCP velocity components resolved along Principle Component directions (Figures $7 \mathrm{a}$ and $7 \mathrm{~b}$ ) for ( $\mathrm{a}$ and $\mathrm{c}$ ) Eva Island and ( $\mathrm{b}$ and d) Pith Reef. Top panels show the major axis component ( $\mathrm{V}$, essentially along-shelf), while lower panels show the orthogonal across-shelf flow $(\mathrm{U})$. The rotation direction coincides with $+\mathrm{V}$.

[44] A ship-mounted ADCP transect obtained on 27 March (Figure 11) coincided with the eastern section (CTD Stns 87 to 86) of the CTD transect conducted at the same time off Zoe Bay (Figure $8 b$ ). The independent variable, time, is a surrogate for across-shelf distance, given the transect was observed by proceeding from the east (offshore) to the west (onshore). For this plot the principle component directions calculated over the duration of the transect (about $45 \mathrm{~min}$ ), were aligned quite closely to the north, $\mathrm{v}$ and east, $\mathrm{u}$, compass directions, so the velocity data are presented relative to these directions, instead of being rotated to the principle axis. The cross-stream component (Figure 11a) is the most interesting with a band of eastward (offshore) flow reaching $7 \mathrm{~cm} \mathrm{~s}^{-1}$ between bins 9 and 16 near the western end (centered on a time of 1430), with an abrupt transition to westward flow at depth. The transition between eastward and westward flow curves upward to the east and surfaces at about the 1400 position. This location coincides approximately with the location of a convergent color front and presumed plume boundary, as determined visually and photographed from the ship during the survey. Surface convergence was a characteristic and persistent feature of the front all the way from Lucinda Jetty to at least Zoe Bay, as evidenced by extended foam lines and other flotsam strewn along the color front.

[45] Westward flows predominate beneath this curve, with a maximum speed of about $10 \mathrm{~cm} \mathrm{~s}^{-1}$. Weak northward flows predominate near the surface and offshore (Figure 11b) with a core of southward flow evident at the nearshore end of the transect, centered near bin 12 at time 1437. The overall structure suggests a convergent frontal structure with plume water flowing northeastward nearshore and in the near surface, and northwestward flow to seaward, beneath the frontal interface.

[46] The structure shown in Figure 11 is consistent with the mean velocity profiles at Eva Island and Pith Reef discussed above (Figure 9). For the cross-stream component, $\mathrm{U}$, there is a tendency for westward flow in the upper part of the water column (but with a reversal, near surface in the shipboard data), and for eastward flow at depth offshore (Figure 9d). Flow tends westward almost everywhere at Eva Island with a weak tendency for reversal in the middle of the water column. For the along-stream component, V, stronger northward flow also prevails at the surface, nearshore with a tendency for southward flow at depth (Figure 9a), while flows tend southward offshore near the surface and northward at depth (Figure 9b).

[47] The general consistency between the three methods of data presentation is reassuring, but there are significant differences that might be attributed to local tidal variability, the spatial separation between Eva Island and Pith Reef, on the one hand, and the Zoe Bay transect on the other. Additionally, we are comparing an essentially instantaneous profile affected by tidal and other high-frequency motions with a time series or mean obtained over a monthly timescale.

\section{Discussion}

\subsection{Dynamical Classification}

[48] It is instructive to classify the observed plumes within a dynamically consistent framework that allows 
(a) Eva Island ADCP Vely All bins Rotated 339.5 (deg)

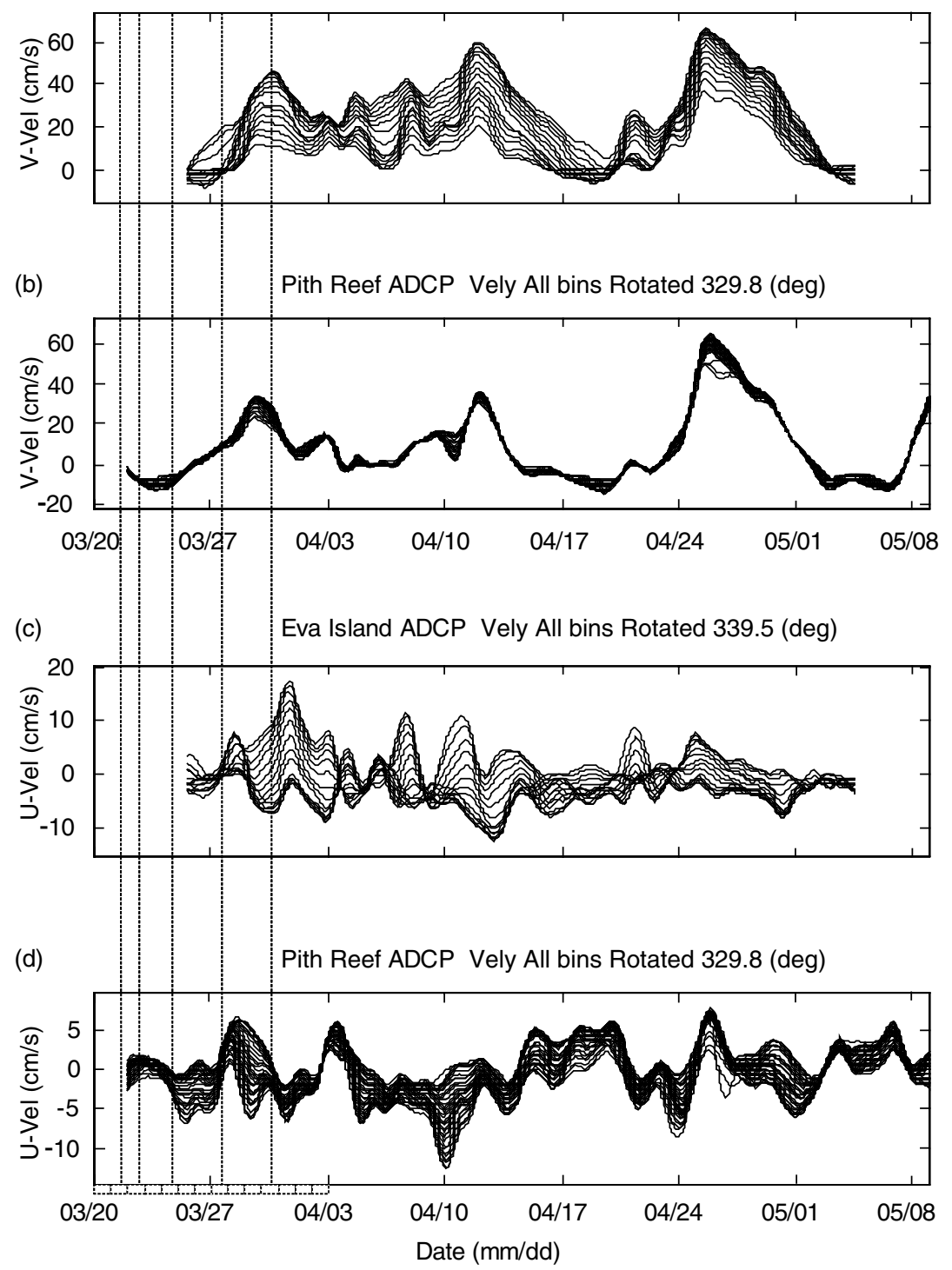

Figure 10. Time series of low-frequency ( $a$ and b) along-shelf and (c and d) across-shelf currents at (a and c) Eva Island and (b and d) Pith Reef ADCP sites. Strong shear is evident in both components of velocity at Eva Island, while the along-shelf component at Pith Reef is nearly barotropic.

comparison with plumes that occur elsewhere. This could also guide future applications of hydrodynamic modeling techniques to the Herbert and Tully River plumes. In principle, various classification schemes could be applied [e.g., Chao, 1988; Kourafalou et al., 1996; Pullen and Allen, 2000]. That of Chao [1988] employs just two dimensionless parameters. The first is a Froude number equal to the ratio of the inflow velocity to the first baroclinic mode phase speed, determined at the estuary mouth. In the inviscid limit, Froude numbers exceeding unity imply the plume is supercritical. However, plumes with Froude numbers less than unity may be supercritical if dissipation is sufficiently high. The second is a ratio of the downstream intrusion speed and the theoretical phase speed, which is a measure of the dissipation. However, this scheme is difficult to apply to field experiments such as ours, where the initial development of the plume was not observed, and where the downstream front location is difficult to define due to mixing and diffusion or to coalescence with other plumes. Since Froude numbers where less than unity on 21 March and decreased thereafter, we cannot determine whether the plume was super or subcritical, i.e., how important dissipation was, without knowing the downstream propagation speed.

[49] The classification scheme of Garvine [1995] is more general, in that it accounts for a variety of forcings, and it is more easily applied using our airborne and in situ observations to determine the relevant parameters. In this scheme the dissipation issue is resolved by assigning a representative value to the linear friction coefficient, which depends on whether the plume is attached to the bottom (bottom friction) or separated from it (interfacial friction). The scheme sorts buoyant plumes and coastal jets into a hierarchy based on the Kelvin number, K, a nondimen- 


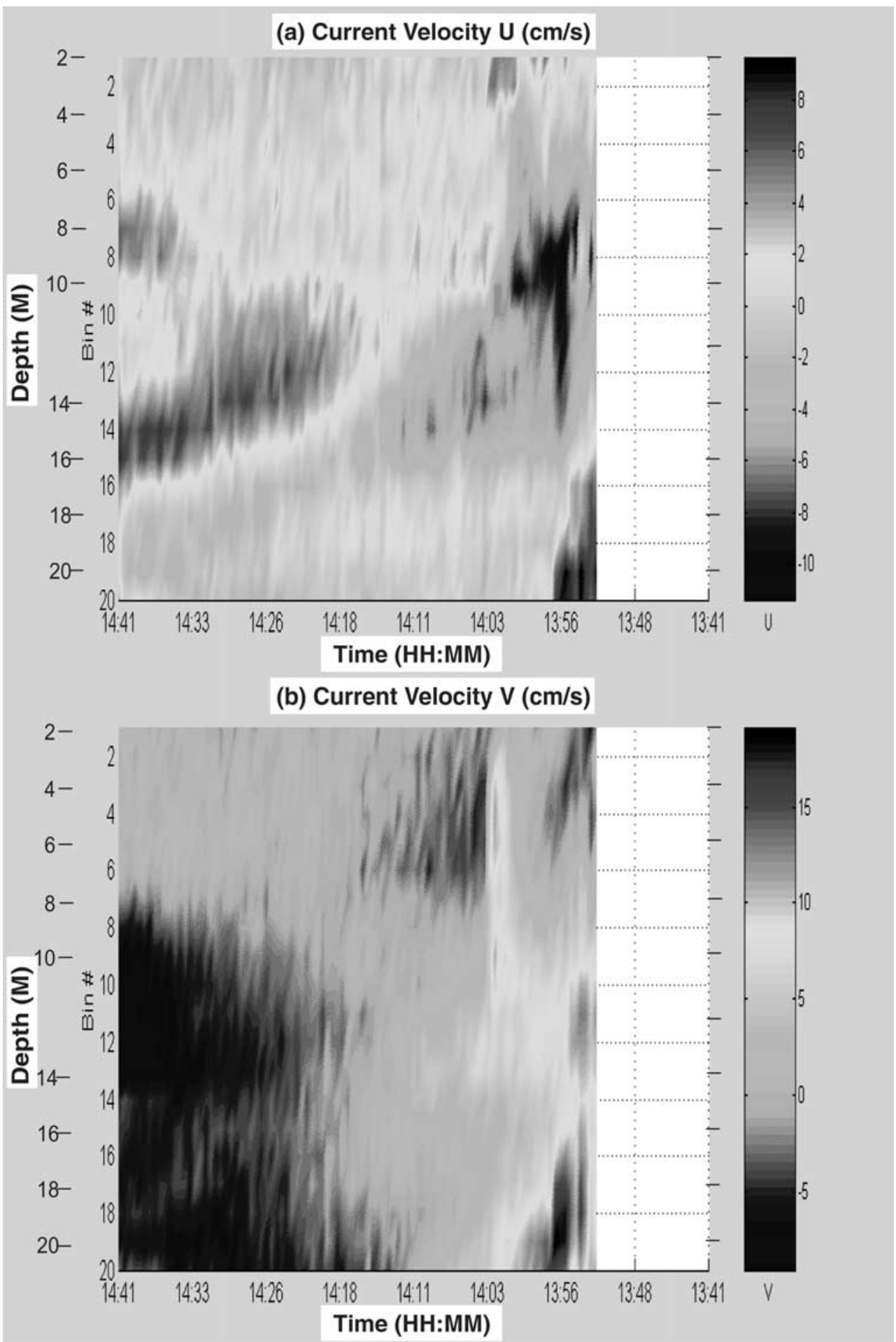

Figure 11. Vertical section of instantaneous current velocity across the plume and frontal boundary from the shipboard ADCP. This coincides with the CTD transect (Stns 87-86) obtained off Zoe Bay (Figure 10b). Strong vertical and horizontal shear (up to $20 \mathrm{~cm} \mathrm{~s}^{-1}$ contrast) is evident in (a) the velocities, $U$, transverse to the frontal interface, while horizontal shear dominates in (b) flows, V, parallel to the front. See color version of this figure at back of this issue.

sional ratio of plume width scale versus the baroclinic Rossby radius. Within this scheme other nondimensional parameters such as the Froude number, F, and internal wave phase speed, c, play an important secondary role that allows more subtle plume characteristics to be distinguished. Additional parameters specify the aspect ratio, Gamma, of the plume or its reciprocal, and the scaled Ekman transport and linear drag coefficient. The last two effectively account for 
wind and bottom stress, taking into account the effects of rotation. Assuming the pressure (or buoyancy) effects are of first order, these quantities may be used to determine the relative importance of other steady state terms to the alongstream and across-stream momentum balance [Garvine, 1995].

[50] Since the scheme assumes steady state dynamics, plumes for which the forcing and/or plume geometry changes significantly over a period of less than a week might not be reliably classified. The scheme, which is diagnostic rather than prognostic, also relies on prescription of bulk characteristics of the plume, which must be determined from field or lab work, or from a numerical hydrodynamic model.

[51] The Herbert, Tully, and Burdekin Rivers classifications (Table 2, cases 1-4) were made on the basis of parameters derived from the sea surface salinity maps and in situ data, such as plume width and representative buoyancy frequencies. These are compared with selected cases from the work of Garvine [1995], which either span his full range or are comparable with our plume classifications, at least as far as $\mathrm{K}$ is concerned. The negative values result from the Southern Hemisphere location, and signify the tendency for austral plumes to turn left rather than right as they cross the shelf under the influence of Earth rotation $(\mathrm{f}<$ $0)$, but are otherwise of little diagnostic consequence. Case 1 is based on estimated mean quantities for the Herbert over the 10 day flight period; parameterizations based on data from specific days yielded similar results, giving us confidence to apply the scheme to the time-varying Herbert River plume. However, we found that the corresponding momentum term scalings (not shown) suggest there is a momentum deficit that might be explained by the absence of a time-varying (local) acceleration and related tidal stresses.

[52] The results for the Herbert plume show clearly that the Kelvin number is of order 1 , and so neither of the simplified extreme cases $(K \ll 1$ or $K \gg 1)$ discussed by Garvine are applicable. This implies the river falls squarely between the advection-dominated Point Beach plume (case 5), and the geostrophic Scottish Coastal Current (case 10). The Froude number is of order 0.1, suggesting that the observed plume is subcritical and consequently is unlikely to form an initial bulge wider than the associated downstream coastal current. The Coriolis term dominates advective accelerations, and the wind and bottom friction are of roughly equal importance, but both are dominated by the pressure (buoyancy forcing) term. The apparent "missing" momentum on the acceleration (left) side of the momentum equation, however, argues against making the geostrophic approximation for this plume. On the contrary, it appears that any modeling effort for the Herbert should incorporate a full (nonsteady) momentum formulation, possibly with provision for both tidal and subtidal forcing to effectively capture the unsteady dynamics.

[53] The Tully River plume (case 2) displays a dynamically wider plume structure $(\mathrm{K} \sim 2)$, although the data are confined to only a couple of days, and may be biased by transients. Also, the along-shore extent of the plume might not have been captured by the corresponding surface salinity map. Its Froude number is about double that of the Herbert, but is still subcritical $(\mathrm{U} \ll \mathrm{c})$, in contrast to the Mississippi and Niagara Rivers which are critical (cases 6 and 8), and Point Beach (case 5) which, according to Garvine's analysis, is quite narrow $(\mathrm{K} \sim 0.1)$ and supercritical $(U>c)$. Parameters for the observed Burdekin River flood plume (case 3) are comparable with those of the Tully, although both the wind and bottom stress effects are smaller. This may be compared with the larger Burdekin River flood plumes observed by Wolanski and Jones [1981] and Wolanski and van Senden [1983] and modeled diagnostically by Burrage et al. [1995] (case 4). Both these sets of authors assumed the plume was in geostrophic balance. However, the scaling suggests wind effects could be quite important, while friction is of secondary importance, given the plume was mainly above, rather than attached to, the bottom.

[54] A useful aspect of plume classification is that it suggests comparisons with plumes located in other geographical and oceanographic settings. Our classification and Garvine's, suggest the dynamics of the Herbert River plume could be fruitfully compared with those of the Niagara River (case 8) studied by Masse and Murthy [1990, 1992], and the Alaska Coastal Current (case 9) [Royer, 1981a, 1981b]. Both of these have $\mathrm{K} \sim 1$, but faster ambient flows and lower susceptibility to wind and bottom (or interfacial) stress, mainly because of the stronger rotational effects (larger f). A reviewer has pointed out that the deeper water underlying the Alaska Coastal Current would also tend to diminish the role of bottom stress. Conversely, this emphasizes the fact that at tropical and subtropical latitudes (as in the GBR Lagoon), and in shallower locations, wind and bottom or interfacial stresses are less constrained by the effects of rotation, and thus capable of disturbing the plume geometry and dynamics, especially under conditions of extreme variability, such as during the passage of a tropical cyclone. Thus plumes that turn left upon entering the GBR Lagoon, particularly in the northern GBR, where $f$ is smaller, and the water is relatively shallow, might do so as much because of the prevailing wind field, as because of Coriolis deflection.

[55] The comparison with the Niagara River plume is interesting because that plume was initially attached to the bottom before it lifted off and turned inertially in an anticyclonic direction. These features are shown clearly by the Herbert River (Figures $3 \mathrm{c}$ and $8 \mathrm{a}-8 \mathrm{~d}$ ). It also has other important implications. Masse and Murthy [1990] found that mixing between the anticyclonic plume and the ambient water under downwelling-favorable winds was limited, while seaward flow associated with upwellingfavorable winds enhanced mixing. This latter situation could readily arise in the GBR if a land-falling tropical cyclone crosses the coast close to the catchment and expands into a slow moving tropical rain depression. We have not yet had the opportunity to observe plumes under persistent upwelling-favorable winds using the SLFMR, but the ecological effects of such events on coral reefs in the region could be quite significant, and warrants further investigation.

[56] Our limited results for the Tully suggest that it could be comparable with the Gaspe Current (case 7), at least under the circumstances observed, with $\mathrm{K} \sim 2$ and comparable $\mathrm{F}$, but the aspect ratio for the Gaspe is significantly higher (observed length versus width) despite its being dynamically wider (width compared with baroclinic Rossby 
radius), and the wind and frictional effects are again more constrained.

[57] The temperate, but nearly subtropical Mississippi River (case 6) forms an interesting contrast with both the Gaspe and the Tully. The Mississippi is dynamically much narrower $(\mathrm{K} \sim 0.2)$ and dominated by advection $(\mathrm{F} \sim 1)$, but it could exhibit larger friction effects, while wind stress is of intermediate significance; in this respect it resembles the Tully River dynamically more than does the Gaspe.

[58] An interesting issue is whether the scheme can usefully characterize and distinguish transient stages in the development of a particular plume event. This could be particularly important in tropical and subtropical rivers, particularly in Australia, where a river may go from almost dry or low base flow to a raging torrent in a matter of a few days, a period that falls short of the $\sim 1$ week limit imposed by the assumed steady state dynamics of the classification scheme. The scheme could be usefully extended to handle non steady dynamics to help assess the importance of such transients. Including the local acceleration term in the momentum balance would be one step in this direction but such influences as tidal mixing on the buoyancy structure, and of tidal ("Reynolds") stress on the low-frequency currents, might then have to be considered explicitly.

\subsection{Characteristic Dynamical Features}

[59] The preceding plume classification shows clearly that a variety of forcing mechanisms, and hence momentum sources, need to be accounted for in determining the dynamics of the Herbert and Tully River plumes. It is also clear that the transient features of the plume could complicate or even invalidate the classification in this case. We now reexamine the key features of the plume as it evolved during the intensive period of the experiment (as described in section 3.2.2). Our goal is to define the momentum sources and transfer mechanisms that might have dominated the plume dynamics and its response at the time of each flight. This provides a basis for comparison with other studies, and lays a foundation for analyzing our more recent surveys of the wind-dominated Johnstone and Russell/ Mulgrave River plumes conducted in February 2001 (to be reported elsewhere).

\subsubsection{Wind Forcing}

[60] The first flight, on 21 March, was preceded by a short (1 day) burst of northward along-shelf wind stress with a representative magnitude of $0.1 \mathrm{~Pa}$ and peak of $0.2 \mathrm{~Pa}$ (Figure 6d). This wind stress impulse subsequently strengthened and veered toward the west and was augmented by the land breeze associated with the diurnal wind pattern. The wind impulse was thus downwelling favorable, but in a direct, rather than Ekman sense, because the duration was short in comparison with the local inertial period (37.8 hours). This wind event appears to have narrowed the plume. A day later, on 22 March, after the wind relaxed, it had expanded in width by a factor of about two (from 9 to $17 \mathrm{~km}$ ) off Hinchinbrook Island, despite the diminishing river discharge.

[61] Wind effects on plumes and coastal currents have been addressed by Munchow and Garvine [1993], Kourafalou et al., [1996], Xing and Davies [1999], and Fong and Geyer [2001], among others, but these studies generally treat more persistent wind events. Fong and Geyer [2001] show a temperate model plume responding significantly to steady upwelling-favorable wind stress events of 0.05 and $0.2 \mathrm{~Pa}$ within $12-24$ hours of the wind being "turned on." However, the event we observed was a brief impulse, short in comparison with the Ekman spin up time, which is more protracted at tropical latitudes.

[62] Pullen and Allen [2000] model a more realistic and relevant case. Their model Eel River plume is subject to realistic downwelling-favorable wind stress for several days after which the wind weakens, swings anticyclonically, then strengthens in an upwelling-favorable direction that persists for several days (see their Figure 8). The plume responds dramatically. After first being narrowed against the coast by the downwelling winds, the downstream section of the plume expands seaward and separates from the coast. This is similar to the response that we observed on 27 March to relaxation of downwelling winds. As the wind and coastal currents reverse direction more saline shelf water penetrates the center of the plume, which is displaced in the upcoast direction (in the opposite direction to coastal-trapped wave propagation). An anticyclonic eddy forms, spun up by across-shelf shear of the along-shelf current, which reverses earlier near the coast; and the plume rotates and develops an arcuate (or hook-shaped) frontal structure around its limb, on the upcoast side of the river entrance. These two studies and suggestions by Kourafalou et al. [1996] hint that relaxation of a downwelling wind event, in itself, could lead to a significant upwelling response, as the plume adjusts toward a new dynamic equilibrium. The arcuate frontal structure of the Pullen and Allen's study visually resembles that mapped during our flight of 27 March, as discussed in section 5.2.3 below.

\subsubsection{Boundary Currents}

[63] On 24 March the width of the plume and salinity of its frontal transition zone ( $32 \mathrm{psu}$ ) were still as wide as on 22 March, but a combination of tidal action and southward drift with moderate ambient vertical shear (Figures 10a and 10c) had evidently mixed the plume interior to the extent that the surface salinity had risen by $10 \mathrm{psu}$. The tides weakened as the neap approached (Figures 5e and 6c), and wind and wave conditions were calm (Figures $6 \mathrm{~d}$ and $6 \mathrm{e}$ ). The only significant forcing at this time, apart from the moderating river discharge was the $8 \mathrm{~cm} \mathrm{~s}^{-1}$ southward along-shelf drift.

[64] Conditions during the flight on 27 March were similar to those of 24 March, except that tides were at minimum (neap) intensity (Figures 5e and 6c) and the ambient depth-averaged along-shelf drift was essentially zero (Figure 6b). However, the latter was in the process of reversing to a northward direction. Indeed, seaward of the plume at Pith Reef, where the along-shelf flow was essentially barotropic, the flow had already reversed and was flowing northward at about $8 \mathrm{~cm} \mathrm{~s}^{-1}$ (Figure 10b). The along-shelf currents were thus sheared horizontally. The tendency for flow reversal was also accompanied by significant vertical shear at Eva Rocks, i.e., inside the plume body (Figure 10a) where the top 3 ADCP bins indicate upper layer surface currents reached $20 \mathrm{~cm} \mathrm{~s}^{-1}$, while the bulk of the underlying water was stagnant. These results are consistent with a reversal of the prevailing continental shelf currents that are modulated by the East Australian Current on synoptic scales and also subject to remotely forced coastal-trapped waves [Burrage et al., 1991, 1994]. 
[65] While the well-developed arcuate frontal structure observed during the flight of 27 March visually resembled that reproduced in model results obtained by O'Donnell [1990] and Pullen and Allen [2000], the prevailing forcing conditions were quite different as were certain aspects of the response. Significantly, there were no wind events influencing the Herbert River plume at this time, and the hookshaped structure formed on the downcoast side of the channel entrance, rather than on the upcoast side, as in their experiment. The conditions on 27 March included a vertically sheared (baroclinic) along-shelf ambient flow for which the depth-averaged (barotropic) component was instantaneously zero but reversing in direction, with negligible wind stress and weak tides. In contrast, the conditions imposed on the models of O'Donnell [1990] and Pullen and Allen [2000], which produced similar-looking structures, involved moderately strong barotropic ambient cross flow, and wind stress reversing from downwelling to upwelling favorable, respectively.

[66] The remarkable similarity in plume structure likely arises from more subtle aspects of the forcing and resulting currently velocity field that are actually common to both the modeling studies and our field observations. First, near the surface, the cross-flow associated with the vertical shear in the (baroclinic) along-shelf current evidently sharpened the upstream boundary of the Herbert River front, much as the ambient barotropic cross flow sharpened the front in O'Donnell's study. Second the ambient along-shelf current was decelerated or reversed, and also sheared horizontally across the shelf. The resulting strain produced changes in the position, orientation and curvature of the frontal boundary. The wind stress reversal in Pullen and Allen's experiment also changed the direction and intensity of the along-shelf flow. Both vertical and horizontal shear were features of the model results obtained by O'Donnell [1990] and Pullen and Allen [2000], and of our observations. We thus hypothesize that the observed hook-shaped structure may be generated by any mechanism producing a changing boundary stress distribution and/or body force that appropriately modifies the dynamical balance, and is accompanied by enhanced ambient shear. Accordingly, we recommend that future modeling studies investigate momentum transfer mechanisms in which a dynamical equilibrium is first established for a variety of initial states, then changed by transient reversal or relaxation of the relevant forcings, and in which horizontal and vertical ambient current shears are a significant feature. Examples include relaxation, but not necessarily reversal, of a downwelling-favorable wind stress, relaxation and/or reversal of an along-shelf pressure gradient due to an offshore boundary current, and imposition of a propagating long-period coastal-trapped wave. We anticipate that the resulting plume responses will share a number of features in common with the experiments performed to date, which appear to have focused mainly on the effects of constant or stepwise changes in inflow rate, ambient along-shelf current and wind stress, rather than on more or less intense, but continuous changes in such forcing variables.

\subsubsection{Plume Attrition}

[67] Reduction of the river discharge almost to base flow levels and a number of other factors conspired to virtually eliminate the plume by 30 March. These factors included a local maximum in horizontal shear, strengthening tidal currents, and intensified wind stress and wave action; all of which would be expected to mix the diminishing freshwater pool with the saltier shelf waters. They also included a stronger northward ambient flow, which would tend to reduce the plume width. The absence of any obvious point source at the river mouths suggests that the low-salinity values along the coasts were related either to local springs or freshwater seepage along beaches (a line source) and/or the contaminating effect of land in the main beams or sidelobes of the SLFMR (BHMSP). In either case, this sets a maximum timescale of 3 days for attrition of the Herbert and Tully River plumes from a situation of modest but reducing inflow, coupled with enhanced mixing due to moderately intense tidal currents, wind stress and wave action.

\section{Conclusions}

[68] We have reported an integrated airborne sea surface salinity remote sensing and in situ survey of river plumes in the GBR Lagoon. The study domain is an integral part of the GBR World Heritage Area, which is of unique ecological and economic significance, regionally, nationally and internationally. To the best of our knowledge, the study comprises the first application of an airborne sea surface salinity imaging device to river plume studies outside the United States. The results demonstrate the utility of the method that combines spatially extensive and quantitative sea surface salinity distributions obtained from an aircraft with Eulerian time series of meteorological and oceanographic forcing variables observed from in situ platforms.

[69] The development and evolution of the Herbert and Tully River plumes were adequately resolved and tracked using a succession of 5 flights of the passive microwave salinity mapper, the SLFMR, and sea surface salinity maps were produced at intervals of 3 days or less, over a 10 day period. The experiment revealed that the size, location and apparent visibility of the Herbert River plume varied significantly over several day timescales in response to changes in tidal, wind, wave and ambient current forcing and particularly horizontal shear in ambient currents, while the river input gradually diminished from the initial peak. We made only 2 overflights of the Tully River outflow but these, together with the in situ CTD transects, suggest that, as for the Herbert, the Tully plume reduced significantly in scale due to the combined effects of declining river discharge and enhanced mixing due to winds, waves and/or tidal stirring.

[70] The plumes were classified dynamically using characteristic parameter values derived from the airborne and in situ data and where found to fall into an intermediate Kelvin number class. This indicates that all terms in the momentum balance must be considered in analyzing the plume response to atmospheric and hydrodynamic forcing. Changes in plume characteristics such as plume width and dispersal caused by wind stress and along-shelf flow appeared to be consistent with the results of other studies. However, the occurrence of a characteristic hook-shaped structure that has been reported in previous modeling studies, involving changes in ambient cross flow and reversing winds, was here found to be associated with ambient shear imposed on 
the shelf circulation by a western boundary current, the East Australian Current. This feature appeared in the absence of any significant wind stress and at a time when the tides were in the neap phase of the cycle, so that tidally induced mixing was at a minimum.

[71] The river plumes observed during the intensive mapping experiment were representative of the size and pattern of other events that occurred both prior to this, and afterward while our in situ moorings were in place. Thus, they give a good indication of the spatial influence and structure of plumes that are likely to be associated with future high rainfall/flooding events in the region. In the vicinity of Hinchinbrook Island and Rockingham Bay, the Herbert and Tully River plumes followed the coast equatorward as a band of relatively fresh water, which was generally restricted to the inner half of the GBR Lagoon ( $\sim 15 \mathrm{~km}$ seaward of Hinchinbrook Island), but extended considerable distances $(\sim 50 \mathrm{~km})$ along shore.

[72] Our large-scale survey mosaic, constructed from the 21-23 March Halifax Bay flights (not shown here in its entirety), showed that early in the intensive experimental period, the larger-scale Burdekin River plume reached northward to Hinchinbrook Island, where it was augmented by the flows from the Herbert and Tully Rivers. This produced a continuous band of low-salinity water that hugged the coast north of Townsville and expanded across the shelf as it arrived at the SE mouth of the Hinchinbrook Channel and again in Rockingham Bay. The effects of this more southern source of runoff was manifested by water of intermediate salinity lying southward and seaward of the main Herbert River plume in the two northernmost Halifax Bay flights (Figures $3 \mathrm{a}$ and $4 \mathrm{a}$ ). The merging of such plumes, and possible augmentation by local streamflows and submarine groundwater flow to effectively form a freshwater line source, have the potential to produce a continuous coastal buoyancy current that might persist for a significant fraction of the wet season. This phenomenon warrants more detailed investigation using both field observations and high-resolution numerical hydrodynamic models capable of resolving multiple plume sources over a regional scale.

[73] The accumulated SLFMR and in situ data set do not yet include sufficient cases of plume development under varying conditions to draw any firm conclusions on the likelihood that a large plume would migrate seaward sufficiently to inundate the outer reefs of the GBR. However, there are clear indications of relatively dilute seawater appearing in the Lagoon and along the inner edge of the Barrier Reef in response to the combined inputs of the Burdekin, Herbert and possibly Tully rivers. Only one case of a southward Tropical Cyclone-induced wind stress event was recorded, but the wind evidently reversed direction before the resulting rain produced a significant plume; the possibility remains that a persistent poleward wind, combined with a major flood event, could produce a plume that invades not only the GBR Lagoon, but the coral reefs of the outer barrier. In such a case the enhanced friction due to flow over and between the reefs and the complex flow interactions that ensue would demand fine resolution, careful subgrid-scale parameterization, or both, if the plume is to be successfully simulated numerically. This issue is also a critical one for the management of the GBR World Heritage
Area. Since coral organisms are known to be sensitive to nutrient and sediment loads derived from terrestrial runoff, a capability to observe such events, and to predict the likelihood and extent of freshwater influence would be a useful management tool.

[74] While much as been achieved in modeling plume behavior under a variety of steady or stepwise changing discharge rate, wind stress and prevailing ambient drift, the effects of ambient shear related to spatial and temporal changes in boundary current forcing appears to have been little studied. The variety of circumstances (river discharge, wind, waves, tides and currents) that result in the evolution of a particular plume type in the GBR Lagoon and Reef matrix require further investigation. A combination of additional air and sea surveys to characterize a variety of possible responses and judicious use of high-resolution, fully $3 \mathrm{D}$ stratified numerical hydrodynamic models is probably the best way forward. This approach is almost certainly required to develop an understanding of the dynamics of plume evolution under circumstances likely to be encountered in the GBR. Application of an airborne salinity mapper to observe transient stages in plume development is a significant advance, particularly in tropical regions subject to sporadic, yet extreme, flooding events that may be of high intensity, but of limited duration. River catchment hydrological models could provide an additional dimension that would allow a variety of flood scenarios to be developed to test hydrodynamic ocean model responses for scientific and management purposes.

[75] Acknowledgments. The purchase of the SLFMR was facilitated by an Australian Research Council (ARC) Research Infrastructure and Equipment Fund (RIEF) grant and the GBR campaign was funded primarily by an ARC Large Grant. The authors acknowledge additional funding and in-kind support from the Airborne Research Australia (ARA), the Australian Institute of Marine Science, Flinders University, the Great Barrier Reef Marine Park Authority, and the School of Physical and Mathematical Sciences at James Cook University. ARA was established through funding from the Australian Commonwealth's Major National Research Facilities (MNRF) Program. M. Goodberlet (ProSensing Inc.) built the SLFMR, provided expert advice, and assisted with aircraft installation and flight testing. We thank Cary McLean and Jeff Warbrick (AIMS), Rudi Gaissmaier, Wolfgang Lieff, and Graham Wilkins (ARA), and Ray Casey (JCU) for technical assistance and field support. We also thank the Cessna 404 pilot, Ian Drennan (ARA), and the masters and crews of the R/V Lady Basten and R/V Titan for expert assistance and operational support. Meteorological data were provided by the Australian Bureau of Meteorology and stream gauge data were supplied by the Queensland Department of Natural Resources. Richard Brinkman (AIMS) assisted in analyzing the wave data. Richard Garvine and James O'Donnell provided helpful insights and advice and suggestions for improving earlier versions. Helpful reviews by Thomas C. Royer and a second (anonymous) reviewer are also gratefully acknowledged.

\section{References}

Brodie, J., River flood plumes in the Great Barrier Reef Lagoon, in Great Barrier Reef: Terrigenous Sediment Flux and Human Impacts, edited by P. Larcombe et al., Current Research, second edition, November, pp. 3339, CRC Reef Res. Cent. and Earth Sci. Dept., James Cook Univ., Townsville, 1996.

Brodie, J., in The Water Quality Status of the Great Barrier Reef World Heritage Area, edited by D. Wachenfeld et al., pp. 69-96, Great Barrier Reef Mar. Park Auth., Townsville, Queensl., Australia, 1997.

Brodie, J., A. Steven, and M. Baer, The extent of the river plumes associated with cyclone Sadie rainfall, in Cyclone Sadie Flood Plumes in the Great Barrier Reef Lagoon: Composition and consequences: Proceedings of a Workshop Held in Townsville Oueensland, Australia, $10 \mathrm{No}$ vember, 1994 at the Australian Institute of Marine Science, Gt. Barrier Reef Mar. Park Auth., Workshop Ser., vol. 22, edited by A. Steven, pp. 
27-33, Great Barrier Reef Mar. Park Auth., Townsville, Queensl., Australia, 1997

Burrage, D. M., J. A. Church, and C. R. Steinberg, Linear systems analysis of momentum on the continental shelf and slope of the central Great Barrier Reef, J. Geophys. Res., 96(C12), 22,169-22,190, 1991.

Burrage, D. M., K. P. Black, and K. F. Ness, Long-term current prediction on the continental shelf of the central Great Barrier Reef, Cont. Shelf Res., 14, 803-829, 1994.

Burrage, D. M., K. P. Black, and C. R. Steinberg, Long-term sea-level variations in the central Great Barrier Reef, Cont. Shelf Res., 15, $981-$ 1014, 1995

Burrage, D. M., M. A. Goodberlet, and M. L. Heron, Simulating passive microwave radiometer designs using SIMULINK, Simulation, 78, 3655,2000 .

Burrage, D. M., et al., Structure and influence of tropical river plumes in the Great Barrier Reef: Application and performance of an airborne sea surface salinity mapping system, Remote Sens. Environ., in press, 2002.

Chao, S.-Y., River-forced estuarine plumes, J. Phys. Oceanogr., 18, 72-88, 1988

Donguy, J. R., and C. Henin, Surface waters in the north of the Coral Sea, Aust. J. Mar. Freshwater Res., 26, 293-296, 1975.

Fong, D. A., and W. R. Geyer, Response of a river plume during an upwelling favorable wind event, J. Geophys. Res., 106(C1), $1067-$ 1084, 2001

Font, J., Y. Kerr, and M. Berger, Measuring ocean salinity from space, Backscatter, 11(3), 17-19, 2000

Furnas, M., A. Mitchell, and M. Skuza, in River Inputs of Nutrients and Sediment to the Great Barrier Reef, edited by D. Wachenfeld et al., pp. 46-48, Great Barrier Reef Mar. Park Auth., Townsville, Queensl., Australia, 1997

Garvine, R. W., A dynamical system for classifying buoyant plume discharges, Cont. Shelf Res., 15, 1585-1596, 1995.

Garvine, R. W., and J. D. Monk, Frontal Structure of a river plume, J. Geophys. Res., 79(C15), 2251-2259, 1974

Goodberlet, M. A., Australian Scanning Low-Frequency Microwave Radiometer Test and Acceptance Report, p. 37, Quadrant Eng., Hadley, Mass., 15 Feb. 2000a.

Goodberlet, M. A., Australian Scanning Low-Frequency Microwave Radiometer General Specifications and Data Interface Description, p. 17 Quadrant Eng., Hadley, Mass., 20 Jan. 2000b.

Goodberlet, M. A., Australian Scanning Low-Frequency Microwave Radiometer Software Manual, p. 14, Quadrant Eng., Hadley, Mass., 18 Jan. 2000c.

Goodberlet, M. A., and C. T. Swift, A remote sensing system for measuring estuarine and coastal ocean surface salinity, progress report 2 prepared for NOAA under contract 50-DKNA-1-00119 to U.S. Dept. of Commer., p 111, Quadrant Eng., Hadley, Mass., 1993.

Goodberlet, M. A., C. T. Swift, K. P. Kiley, J. L. Miller, and J. B. Zaitzeff, Microwave remote sensing of coastal zone salinity, J. Coastal Res., 13(2), 363-372, 1997.

Ingram, R. G., Characteristics of the Great Whale River plume, J. Geophys. Res., 86(C3), 2017-2023, 1981

King, B., S. Spagnol, E. Wolanski, and T. Done, Modeling the mighty Burdekin River in flood, in Coastal and Estuarine Modeling, Proc. 5th Int. Conf. ASCE, edited by M. L. Spaulding and A. F. Blumberg, pp. $103-115,1998$.

King, B., F. Mcallister, E. Wolanski, T. Done, and S. Spagnol, River plume dynamics in the central Great Barrier Reef, as Chapter 10, in Coral Reef Processes; Physics-Biology Links in the Great Barrier, edited by R. E. Wolanski, 376 pp., CRC Press, Boca Raton, Fla., 2000.

Klein, L. A., and C. T. Swift, An improved model for the dielectric constant of seawater at microwave frequencies, IEEE J. Oceanic Eng., OE-2(1), $104-111,1977$

Kourafalou, V. H., L.-Y. Oey, J. D. Wang, and T. N. Lee, The fate of river discharge on the continental shelf 1 , Modeling the river plume and the inner shelf coastal current, J. Geophys. Res., 101(C2), 3415-3434, 1996

Lagerloef, G. S. E., C. T. Swift, and D. M. Le Vine, Sea surface salinity: The next remote sensing challenge, Oceanography, 8, 44-50, 1995.
Lerner, R. M., and J. P. Hollinger, Analysis of $1.4 \mathrm{GHz}$ radiometric measurements from Skylab, Remote Sens. Environ., 6, 251-269, 1977.

Le Vine, D. M., M. Kao, R. W. Garvine, and T. Sanders, Remote sensing of ocean salinity: Results from the Delaware Coastal Current Experiment, J. Atmos. Oceanic Technol., 15, 1478-1484, 1998

Marmorino, G. O, and C. L. Trump, High-resolution measurements made across a tidal intrusion front, J. Geophys. Res., 101(C11), 25,661$25,674,1996$

Marmorino, G. O., T. F. Donato, M. A. Sletten, and C. L. Trump, Observations of an inshore front associated with the Chesapeake Bay outflow plume, Cont. Shelf Res., 20, 666-684, 2000.

Masse, A. K., and C. R. Murthy, Observations of the Niagara River thermal plume (Lake Ontario, North America), J. Geophys. Res., 95(C9), 16,097-16,109, 1990.

Masse, A. K., and C. R. Murthy, Analysis of the Niagara River plume dynamics, J. Geophys. Res., 97(C2), 2403-2420, 1992.

Miller, J. L., Airborne remote sensing of salinity, Backscatter, 11(3), 24$27,2000$.

Miller, J. L., M. A. Goodberlet, and J. B. Zaitzeff, Remote sensing of salinity in the coastal zone, Eos Trans. $A G U$, 79(14), 3, April 71998.

Munchow, A., and R. W. Garvine, Buoyancy and wind forcing of a coastal current, J. Mar. Res., 51, 293-322, 1993.

O'Donnell, J., The Formation and Fate of a river plume: A numerical model, J. Phys. Oceanogr., 20, 551-569, 1990.

O’Donnell, J., G. O. Marmorino, and C. L. Trump, Convergence and downwelling at a river plume front, J. Phys. Oceanogr., 28, 1481-1495, 1998.

Pickard, G. L., J. R. Donguy, C. Henin, and F. Rougerie, A Review of the Physical Oceanography of the Great Barrier Reef and Western Coral Sea, Aust. Inst. of Mar. Sci. Monogr., vol. 2, p. 134, Aust. Gov. Publ. Serv, Canberra, 1977

Pullen, J. D., and J. S. Allen, Modeling studies of the coastal circulation off northern California: Shelf response to a major Eel river flood event, Cont. Shelf Res., 20, 2213-2238, 2000.

Royer, T. C., Baroclinic transport in the Gulf of Alaska, part I, Seasonal variations of the Alaska Current, J. Mar. Res., 39, 239-249, 1981a.

Royer, T. C., Baroclinic transport in the Gulf of Alaska, part II, A fresh water driven coastal current, J. Mar. Res., 39, 251-265, 1981 b.

Stieglitz, T., and C. R. Steinberg, AIMS Data Report: Remote Sensing of Sea Surface Salinity, Ground Truthing March 2000, p. 68, Aust. Inst. of Mar. Sci., Townsville, Australia, 2001.

Tomczak, M., and J. S. Godfrey, Regional Oceanography: An Introduction, p. 442, Pergamon, New York, 1994.

Wachenfeld, D., J. Oliver, and K. Davis (eds.), State of the Great Barrier Reef World Heritage Area Workshop, Proceedings of Technical Workshop Held in Townsville, Queensland, Australia, 27-29 November, p. 561, Great Barrier Reef Mar. Park Auth., Townsville, Queensl., Australia, 1997.

Wolanski, E., Physical Oceanographic Processes of the Great Barrier Reef, 194 pp., CRC Press, Boca Raton, Fla., 1994.

Wolanski, E., and M. Jones, Physical properties of Great Barrier Reef Lagoon waters near Townsville, I, Effects of Burdekin River floods, Aust. J. Mar. Freshwater Res., 32, 305-319, 1981.

Wolanski, E., and D. van Senden, Mixing of Burdekin River flood waters in the Great Barrier Reef, Aust. J. Mar. Freshwater Res., 34, 49-63, 1983. Xing, J., and A. M. Davies, The effect of wind direction and mixing upon the spreading of a buoyant plume in non-tidal regime, Cont. Shelf Res., 19, $1437-1483,1999$.

D. M. Burrage, Department of Marine Science, University of Southern Mississippi, Box 1020, Stennis Space Center, MS 39529, USA. (burrage@usm.edu)

J. M. Hacker, Airborne Research Australia, Hangar 60, Dakota Drive, Parafield Airport, Adelaide, South Australia, 5106, Australia.

M. L. Heron and A. Prytz, School of Mathematical and Physical Sciences, James Cook University, Townsville, Queensland, 4811, Australia. C. R. Steinberg and T. C. Stieglitz, Australian Institute of Marine Science, PMB No. 3, Townsville, Queensland, 4810, Australia. 


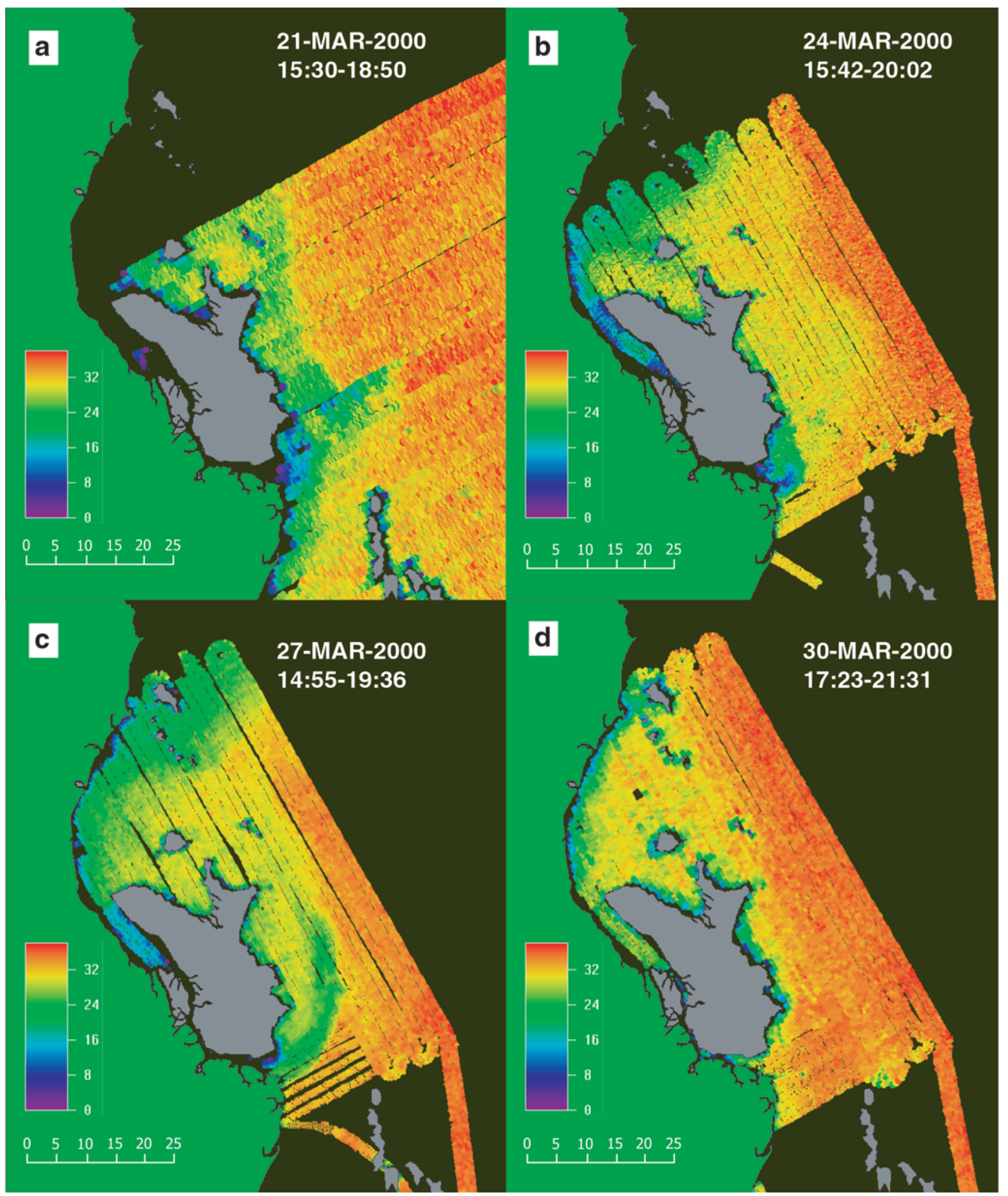

Figure 3. Sea surface salin ity maps from the SLFMR. (a) Partial plot of flights 21 and 22 March that were juxtaposed. Subsequent flights on (b) 24 March, (c) 27 March, and (d) 30 March. Strong surface salinity gradients are prominent in all the maps with freshwater $(<16 \mathrm{psu})$ in the Hinchinbrook Channel and along the coasts, and a transition zone of intermediate salinity (30-34 psu) mark the plume boundary. 


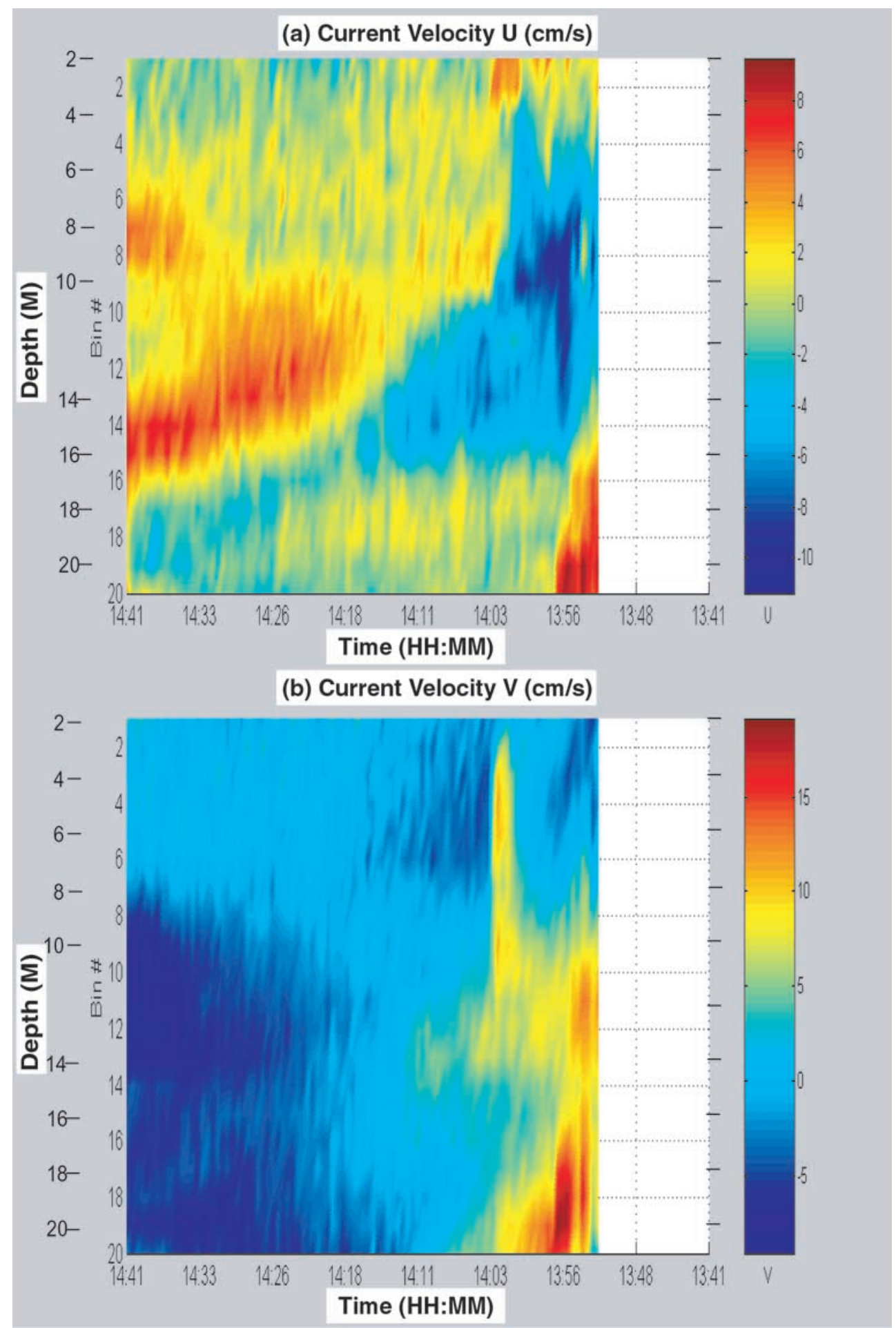

Figure 11. Vertical section of instantaneous current velocity across the plume and frontal boundary from the shipboard ADCP. This coincides with the CTD transect (Stns 87-86) obtained off Zoe Bay (Figure 10b). Strong vertical and horizontal shear (up to $20 \mathrm{~cm} \mathrm{~s}^{-1}$ contrast) is evident in (a) the velocities, $\mathrm{U}$, transverse to the frontal interface, while horizontal shear dominates in (b) flows, $\mathrm{V}$, parallel to the front. 